\title{
El "campo de hoyos" calcolítico de Fuente Celada (Burgos): datos preliminares y perspectivas
}

\section{The chalcolithic "pit field" of Fuente Celada (Burgos): preliminary data and perspectives}

\author{
María del Carmen Alameda Cuenca-Romero*, Eduardo Carmona Ballestero**, \\ Silvia Pascual Blanco*, Gerardo Martínez Díez*, Cristina Díez Pastor* \\ * 2B Arqueología y Gestión del Patrimonio S.L. Vitoria, 29 - $8^{\text {o }}$ izda. 09004, Burgos, \\ arqueologia_y_gestion@hotmail.com \\ ** Área de Arqueología, Facultad de Humanidades y Educación, Universidad de Burgos. c/ Villadiego s/n, \\ Burgos, ecarmona@ubu.es
}

Recibido: 31-07-2010

Aceptado: 04-02-2011

\section{RESUMEN}

Se presentan los resultados de la excavación de un yacimiento del tipo "campo de hoyos", en su mayoría calcoliticos precampaniformes con una pequeña zona de ocupación anterior durante el Neolítico. Destaca la presencia de varias inhumaciones humanas en alguno de los hoyos y de restos asociados al hábitat (manteados de barro y elementos de molienda) en una zona, donde debió de estar situado un pequeño poblado de cabañas cuyos restos han desaparecido al estar estratigráficamente colocados en superficie. Todo ello apunta a una estructura de aprovechamiento económico de tipo estable, con inversión a largo plazo en los medios de producción, al contrario de las hipótesis que postulan una economía itinerante durante este periodo de la prehistoria de la submeseta norte española.

Palabras Clave: “Campos de hoyos”. Neolítico. Calcolítico. Sistema economic. Burgos. Meseta Norte

\begin{abstract}
The results are presented of the archaeological excavation of a 'Pit Field' site in the Northern Spanish Plateau. While a small part of the site was occupied during the Neolithic, most of the pits belong chronologically and culturally to the "Pre-Bell Beaker" Chalcolitith period. A few human graves were recovered inside the pits, together with indications of a settlement area (mud fragments used in the huts and stone mortars) whose remains have disappeared due to postdepositional disturbance. The evidence seems to support recent hypothesis claiming a sedentary exploitation of the milieu, with long-term economic investment on the nearby landscape, in opposition to traditional interpretations describing the prehistoric economy of the area as fundamentally mobile.
\end{abstract}

Key Words: 'Pit fields'. Neolithic. Chalcolithic. Economic system. Burgos. Northern Castilian Plateau.

SUMARIO 1. Introducción. 2. Antecedentes y problemática. 3. Intervención arqueológica: metodología. 4. El registro arqueológico. 5. Dataciones Radiocarbónicas. 6. Discusión y conclusiones. 


\section{Introducción}

El trabajo presenta los resultados de la intervención realizada a principios de 2008 en Fuente Celada (Quintanadueñas, Burgos), motivada por la construcción de un parque eólico que afectaba directamente al yacimiento. Hasta ese momento, el conocimiento real del mismo era bastante reducido, ciñéndose a las evidencias superficiales documentadas en sendas prospecciones arqueológicas (Arnaiz Alonso 1989, Palomino Lázaro 2001). La actuación llevada a cabo ha recuperado una información que, aunque no supone una novedad en el marco de la Meseta Norte, constituye un referente de primer orden en un entorno, el valle del Ubierna, donde el vacio de información publicada sobre yacimientos de la Prehistoria Reciente era total. Este trabajo intenta cubrir en parte esta deficiencia y, aunque se centra en una parte del registro, proporciona nuevos datos sobre el Calcolítico del oriente de la Meseta Norte y ciertos fenómenos sociales asociados a él.
El espacio en el que se inscribe el yacimiento se integra dentro de la unidad conocida como Páramos Calcáreos del Arlanzón, una forma de relieve caracterizada por extensas altiplanicies interrumpidas por pronunciadas cuestas, que alcanzan el fondo de los valles con una pendiente bastante acusada -hasta desniveles de $60 \mathrm{~m}$-. Éstos cuentan con vegas anchas cuando están asociados a ríos de entidad como el Arlanzón, Vena, Urbel o Ubierna. Por el contrario, los ríos de menor poder erosivo o arroyos secundarios tan sólo originan pequeños valles incipientes. Esta disparidad erosiva, unida a la composición geológica de los páramos, caracterizada por la alternancia de materiales micénicos de dureza variable -arcillas de gran plasticidad, margas, calizas y arenas-, crea formas particulares en el contorno de las altiplanicies modelando perímetros festoneados, espigones, cerros aislados, etc. Precisamente, Fuente Celada se sitúa en el borde de una extensa altiplanicie del páramo (970 m.s.n.m), el paraje de San Antón, que flanquea el valle del río Ubierna en su tramo final, muy cerca de su confluencia en el río Arlanzón (Fig. 1).

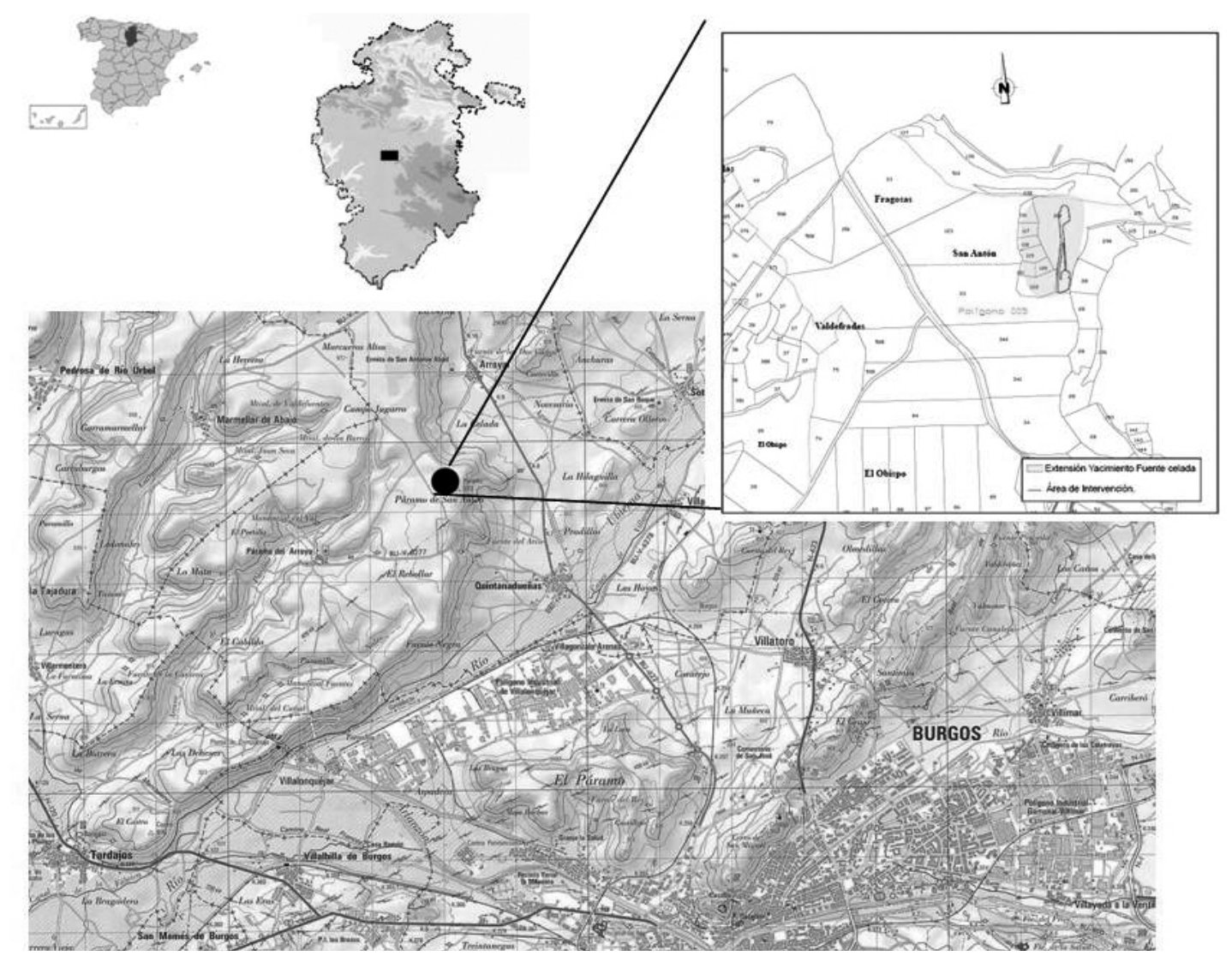

Figura 1.- Localización de Fuente Celada dentro de la provincia y junto a la ciudad de Burgos.

Complutum, 2011, Vol. 22 (1): 47-69 


\section{Antecedentes y problemática}

Como se ha señalado, el conocimiento que se tenía hasta hace poco sobre Fuente Celada era muy somero, reducido a los datos que se sintetizan en la ficha del Inventario Arqueológico de Castilla y León (Arbizu Sagredo 2001). En ella se señala para el yacimiento una extensión de 3,4 ha, a tenor de la dispersión superficial de los materiales arqueológicos, y una atribución calcolítica, debido a la presencia de industria lítica en sílex -lascas simples, una lámina retocada y un frente de raspador- y cerámica a mano de formas simples -cuencos hemiesféricos, algún borde exvasado y fondo plano- $\mathrm{y}$ un buen número de fragmentos con engobe anaranjado en ambas superficies. Como única decoración se señala una digitación en un labio.

Esta información se amplió en el año 2007, debido a la realización de sondeos ante la inminente construcción del parque eólico (Pascual Blanco y Martínez Díez 2008). El objetivo de la actuación era definir las características estratigráficas y tipológicas de Fuente Celada, así como el área y grado de afección que el parque eólico ejercería sobre este lugar. Los resultados mostraron que Fuente Celada era un "campo de hoyos" (Bellido Blanco 1996) con una secuencia estratigráfica vinculada exclusivamente al interior de las estructuras siliformes, dentro de las cuales se documentaron evidencias materiales que se adscribían al mundo calcolítico precampaniforme. Los datos derivados de los sondeos motivaron una actuación arqueológica de carácter preventivo (Martínez Díez et al. 2008), destinada a documentar y registrar las evidencias arqueológicas que se verían afectadas por el citado parque eólico.

La nueva intervención contaba con varias cuestiones de partida que se debían resolver. En primer lugar, determinar la naturaleza de la ocupación vinculada a los hoyos. En este sentido, todavía existen discrepancias entre los investigadores del Calcolítico meseteño acerca de la consideración o no de los "campos de hoyos" como auténticos lugares de hábitat en virtud de la práctica ausencia de restos de cabañas asociados a los hoyos. Las diferencias estriban en cómo se entiende el proceso de formación de estas acumulaciones. Precisamente, los datos derivados de la intervención permitirán discutir entre las propuestas que consideran que se generaron a través de visitas "intermitentes y recurrentes" (Blasco et al. 1994,
Bellido Blanco 1996: 87, Palomino Lázaro et al. 1997), lo que supone una estrategia de hábitat itinerante, o las que abogan por una permanencia mayor e inciden en la nueva lectura del registro (Díaz del Río et al. 1997, Fabián 2006, García Barrios 2007).

En segundo lugar, determinar con precisión la cronología de las entidades arqueológicas documentadas, con el fin de establecer sincronías y diacronías así como reconocer patrones en la distribución espacial de los hoyos.

En tercer lugar, indagar en aquellas particularidades relevantes ofrecidas por el yacimiento. Consideramos que estas pueden aportar datos interesantes sobre aspectos funcionales, económicos, sociales e ideológicos vinculados a las comunidades campesinas responsables de la génesis de tales evidencias arqueológicas. Bajo la aparente homogeneidad de los "campos de hoyos" se reconocen diferencias que aluden (al menos) a diferentes funciones que se pueden vincular al proceso productivo (Díaz del Río y Vicent 2006). De este modo, como línea preferente de investigación se estableció la determinación de los distintos espacios de producción y reproducción social. En este sentido, la faceta más destacada del registro arqueológico fonteceladeño quizá lo constituyan las inhumaciones documentadas. Este es un aspecto habitual en la Meseta Norte, donde algunas estructuras siliformes sirvieron para albergar inhumaciones (Esparza Arroyo et al. 2008; Fabián García 1995; García Barrios 2007: 213-218). No obstante, la asociación de enterramientos con los espacios de hábitat muestra una problemática interesante en el marco de la Meseta Norte, máxime en un momento en que las prácticas funerarias muestran manifestaciones aparentemente divergentes: megalitos segregados de los poblados e inhumaciones en fosa incluidas en los hábitats.

\section{Intervención arqueológica: metodología}

La actuación preventiva llevada a cabo afectó a un área total de $4.930 \mathrm{~m}^{2}$, un $14,5 \%$ de la superficie total del yacimiento. No obstante, no toda el área se sometió al mismo tipo de intervención arqueológica (Martínez Díez et al. 2008). El espacio quedó dividido en dos zonas con estrategias de actuación distintas. Por un lado, una zona de reserva arqueológica $\left(3.580 \mathrm{~m}^{2}\right)$ donde se reconocieron 

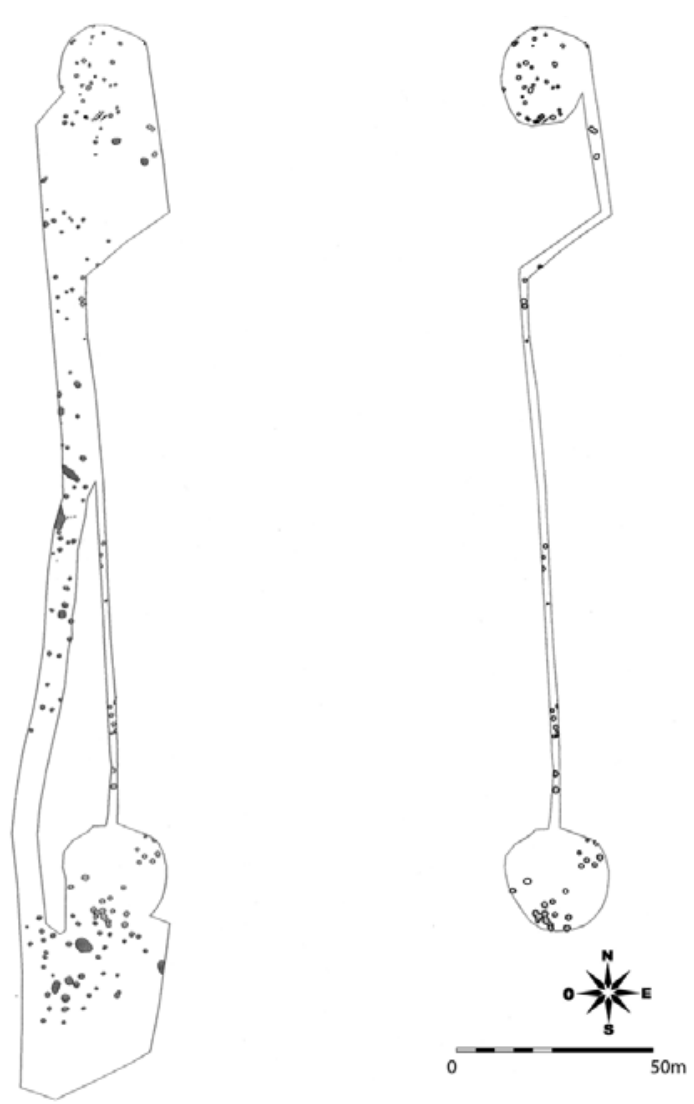

Figura 2.-Planta general de la intervención. A la izquierda: área total intervenida con todas las evidencias documentadas. A la derecha: delimitación del área de las zapatas y zanja eléctrica con las estructuras siliformes excavadas.

127 estructuras negativas (Fig. 2), las cuales sólo fueron objeto de registro topográfico y posteriormente protegidas con medios adecuados. Por otro lado, un espacio de $1.310 \mathrm{~m}^{2}$, el 3,8\% de la superficie, donde se documentaron y excavaron un total de 90 unidades negativas.

Las pautas metodológicas seguidas se ajustan al modelo de excavación estratigráfica con una concepción de las evidencias estratigráficas y sus relaciones basada, a grandes rasgos, en los principios enunciados por Harris (1991) y Carandini (1997). Ahora bien, sin pretender profundizar en los aspectos estrictamente metodológicos, sí queremos realizar varias matizaciones para comprender el registro estratigráfico llevado a cabo. Como es habitual en este tipo de yacimientos, la estratigrafía arqueológica queda restringida a la secuencia formada en cada una de las estructuras negativas y, en algunos casos, a la interrelación existente entre varias de estas estructuras. No existe estratigrafía externa a los hoyos, apareciendo todos ellos cubiertos por el manto vegetal o "nivel de arada". En segundo lugar, se ha utilizado el término "Hecho" para identificar a aquellas entidades superiores a las unidades estratigráficas (UE) reconocibles durante el proceso de excavación. Cabe señalar que no se utiliza como sinónimo de hoyo, fondo, estructura u otros vocablos al uso, sino que simplemente es una herramienta que permite identificar una formación concatenada y coherente de acontecimientos dentro de la estratigrafía, algo semejante a las "actividades" de Carandini (1997). En este sentido, los hoyos se pueden considerar "Hechos" debido a la relación física y delimitación espacial que existe entre los contenedores y sus contenidos. No obstante, la denominación no se ciñe exclusivamente a los hoyos. Sirva de ejemplo que también es posible reconocer "Hechos" distintos dentro de una misma estructura siliforme.

\section{El registro arqueológico}

\subsection{Hoyos y depósitos}

Fuente Celada constituye un buen ejemplo de lo que se conoce como "campo de hoyos", los cuales se caracterizan por una acumulación de estructuras negativas sin una aparente correlación estratigráfica. Precisamente, esta ausencia plantea una problemática que aún no ha sido resuelta convenientemente. Es muy difícil interrelacionar los hoyos entre sí. De esta manera, la información se ciñe exclusivamente al interior de los hoyos, que se convierten en islas de datos difícilmente relacionables.

La excavación arqueológica practicada ha permitido documentar un conjunto estratigráfico compuesto por 85 "Hechos", que, en líneas generales, responden a un esquema secuencial simple: apertura de las estructuras negativas en el sustrato geológico y colmatación de las mismas por una o varias unidades estratigráficas. En algunos casos este patrón se complica con unidades cuyo origen se reconoce en la alteración de las paredes de las estructuras negativas, ya sea en forma de derrumbes o como interfacies negativas más modernas.

Las distintas combinaciones que forman estos tipos de unidades estratigráficas pueden agruparse en los siguientes modelos: 
-Estructuras siliformes: unidades negativas con morfología de hoyo-fosa colmatadas por una o varias unidades horizontales. Es el modelo más frecuente documentado en Fuente Celada (68 casos).

-Fosas de inhumación: únicamente se han diferenciado de las anteriores por su contenido: restos esqueléticos humanos, ya sea de manera individual (Hecho XLIII y Hecho XLIX) o colectiva (Hecho V).

-Conjunto de hoyos: series de estructuras negativas de grandes dimensiones que se cortan unas a otras sucesivamente. Están colmatadas por un depósito superficial homogéneo (Fig. 3).

-Alineación de hoyos de poste: Se trata de pequeñas cubetas - hoyos de poste- rellenas con un sedimento orgánico dispuestas en tres hileras paralelas entre sí, con una orientación Este-Oeste (Fig. 4).

La información recopilada en los hoyos permite indagar sobre patrones espaciales reconocibles a través de las particularidades de cada interfaz y su contenido. Como es habitual en este tipo de yacimientos, la distribución en planta de los hoyos muestra un aspecto aparentemente caótico (Fig. 2). La apariencia enmascara una racionalidad en la distribución que se manifiesta, al menos, en la práctica ausencia de interrelaciones entre las interfacies, que parece ser una pauta recurrente en este tipo de contextos (García Barrios 2007). No obstante, la mera observación no permite reconocer ningún patrón. Para intentar desvelar pautas espaciales se pueden utilizar distintas estrategias que permitan comparar y contrastar la información de los hoyos. En este sentido, parece que las aproximaciones tipológicas ofrecen resultados demasiados ambiguos (Bellido Blanco 1996, García Barrios 2007), por lo que es preferible otro tipo de vías. Una estrategia adecuada es la que considera las diferencias referentes a capacidad volumétrica y el contenido de los hoyos para intentar reconocer espacios con funcionalidades distintas (Díaz del Río et al. 1997).

El cálculo de los volúmenes en litros de los hoyos (Fig. 5) permite comparar las estructuras negativas, más allá de sus atributos formales (Díaz del Río 2001). La observación de este tipo de datos permite agrupar los hoyos en dos conjuntos: los inferiores a 700 litros y los superiores a 1100 litros, algo semejante a lo detectado en el yacimiento madrileño de Las Matillas (Diaz del Río et al. 1997). Admitiendo una función inicial de la mayoría de los hoyos como silos, las diferencias reconocidas en cuanto a la capacidad de almacenaje entre

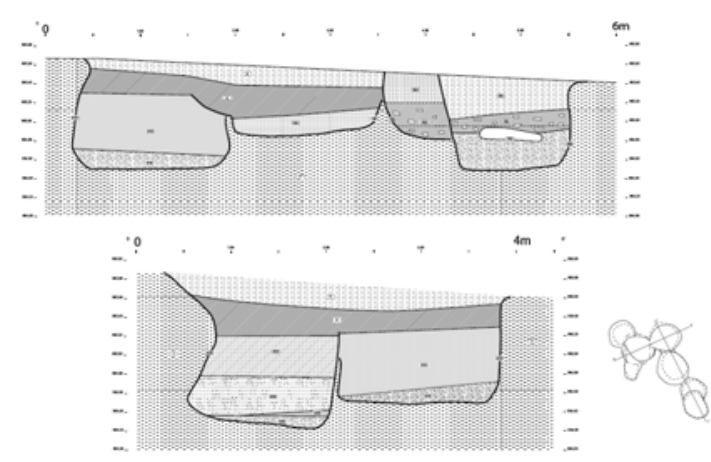

Figura 3.-Sección longitudinal y trasversal del conjunto de hoyos.

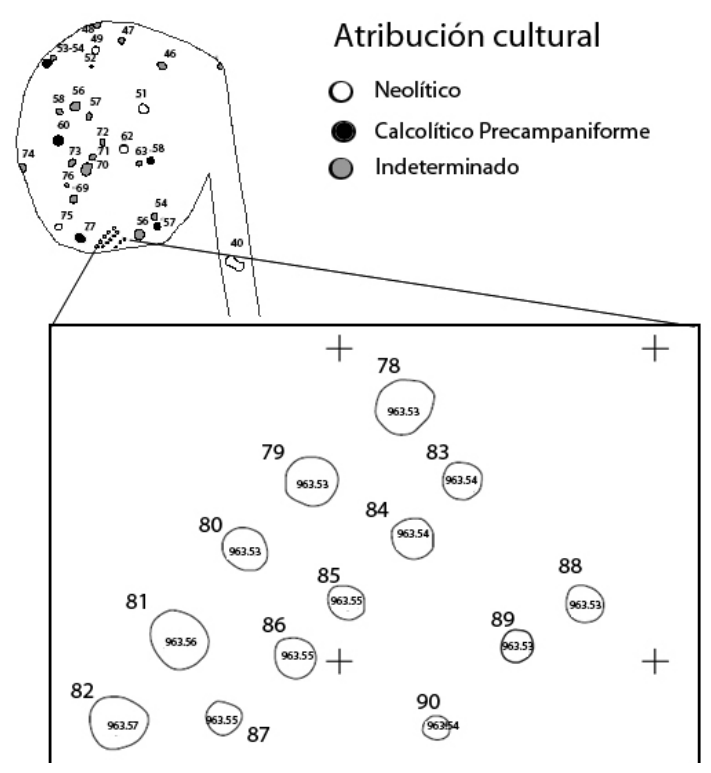

Figura 4.-Planta de la alineación de los hoyos de poste.

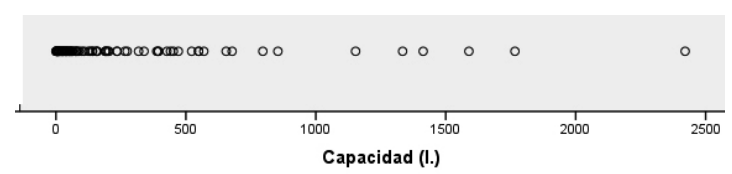

Figura 5.-Distribución por capacidad en litros de los hoyos.

los hoyos de una categoría y otra son significativas, aunque la norma parece ser la construcción de elementos de almacenaje por debajo de los 7001 , superando sólo excepcionalmente este volumen.

La comparación de las capacidades de los hoyos fonteceladeños revela, además, una clara diferencia entre los hoyos situados al sur (sectores II y III) y los ubicados al norte (sector I). Sin embargo, esta 
diferencia parece estar más relacionada con el sustrato geológico que con una distribución funcional diferenciada de los espacios: mientras en el sector I aflora la caliza de páramo, en el resto aparecen margas mucho más blandas, por lo que la capacidad media es mayor en los documentados al sur (sectores II y III). No obstante, es interesante constatar que, en comparación, la capacidad de almacenamiento de los hoyos neolíticos, situados en el sector norte, es significativamente inferior a los calcolíticos.

Otra faceta que puede ofrecer información relevante es la que relaciona capacidad y Número de Restos arqueológicos conservados (NR). La simple observación de los datos (tabla 1) determina que no existe una relación directa entre capacidad y NR. Se pueden observar dos ejemplos sintomáticos: el hoyo 17, de gran capacidad (1589 1.), no ha deparado más que 7 fragmentos de cerámica, por el contrario el hoyo 42, con una capacidad de 265 1., contenía 1554 elementos arqueológicos. Existe, por lo tanto, un depósito diferenciado que no se relaciona directamente con la simple amortización de los hoyos. Por tanto, es posible observar episodios diferenciados y significativos con funcionalidades distintas que delimitan espacios diferentes dentro del proceso de producción. Mientras la mayoría de estructuras siliformes se colmatan con sedimentos que incorporan un número reducido de residuos asociados a espacios domésticos, es posible reconocer dos episodios en los que la amortización de restos es considerable: las vinculadas al hoyo 19 , que incluye un enterramiento, y al hoyo 42 .

También es posible reconocer un área al sur de la intervención (Fig. 6) donde se concentran todos los restos de manteado de barro (hoyos 18, 19, 22, 23, 24, 32 y 42), presumiblemente asociados al recubrimiento de cabañas. En las proximidades de este espacio concreto y delimitado se puede plantear la ubicación del caserío, al menos de la fase correspondiente al Calcolítico inicial, teniendo en cuenta la deposición diferencial de restos en relación a su ubicación originaria. Precisamente, entre los hoyos donde se encontraron los restos de manteado se reconoce un significativo vacio, en el cual entendemos se pudo ubicar el caserío.

\subsection{Cerámica}

El elemento más abundante recuperado en la excavación es la cerámica, cuya cantidad asciende a 4794 fragmentos. El análisis del conjunto ha deparado unos resultados que sintetizamos a continuación. Todo el grupo mantiene unas pautas técnicas comunes derivadas de unas condiciones de producción domésticas, definidas por unos procedimientos técnicos simples y una estandarización laxa. Así, predomina la cocción irregular $(46 \%)$, seguida de la cocción mixta (32\%). Para este tipo de piezas el límite entre ambas es muy difuso, por no decir inexistente, pues se basa en criterios subjetivos del observador. Fruto de este contexto de producción también son los porcentajes de las cocciones reductora y oxidante $(13 \%$ y $9 \%)$. Las coloraciones refuerzan esta apreciación.

En las piezas predomina la variabilidad cromática de las superficies aunque los tonos claros y rojizos son más frecuentes en las caras exteriores, y el negro y las tonalidades pardas y oscuras en las interiores. Todos estos datos sugieren que los reci-

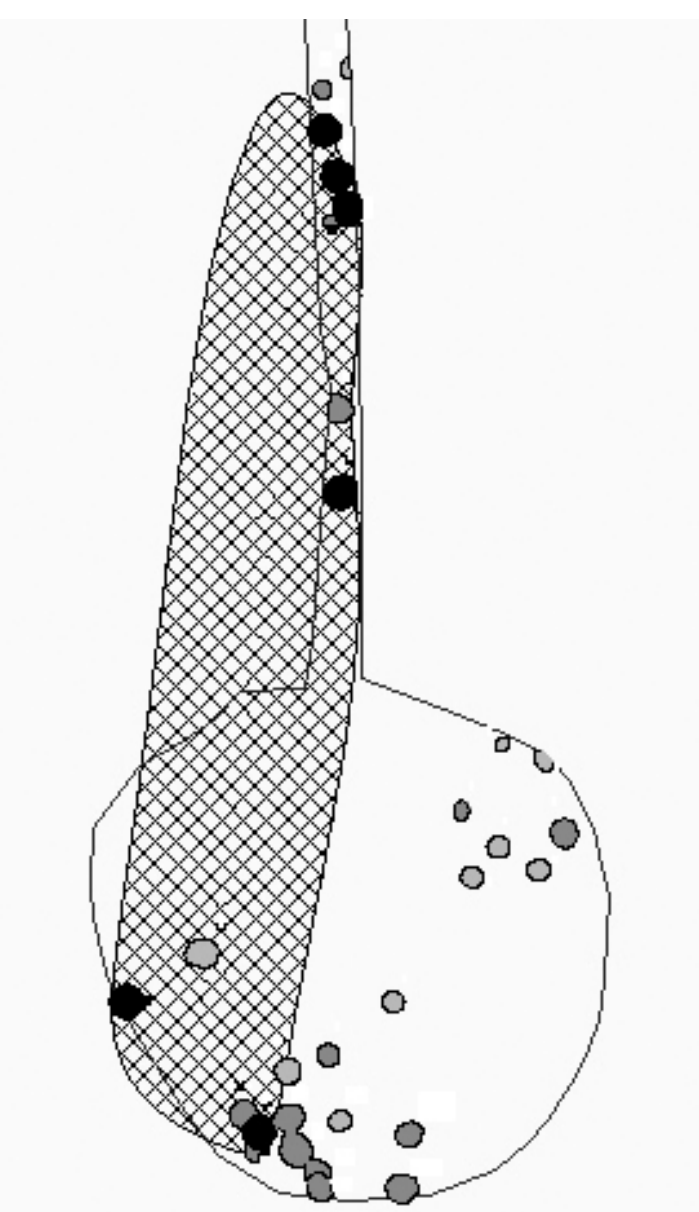

Figura 6.- Espacio delimitado por los hoyos que contienen restos de manteado de barro. 


\begin{tabular}{|c|c|c|c|c|c|c|c|c|c|c|c|}
\hline ID & Tipo & \begin{tabular}{|c} 
Capacidad \\
(l.) \\
\end{tabular} & $\begin{array}{c}\text { Cerámica } \\
\text { (NR) }\end{array}$ & \begin{tabular}{|c|} 
Lítica \\
(NR)
\end{tabular} & \begin{tabular}{|c|} 
Fauna \\
(NR)
\end{tabular} & $\begin{array}{l}\text { Industria } \\
\text { ósea (NR) }\end{array}$ & Inhumaciones & Molinos & $\begin{array}{c}\text { Manteado } \\
\text { de barro }\end{array}$ & Total & Atribución \\
\hline 1 & Hoyo & 25 & 1 & & & & & & & 1 & \\
\hline 2 & Ноyо & 441 & 25 & 1 & & & & & & 26 & Precampaniforme \\
\hline 3 & Hoyo & & 21 & 1 & 5 & & & 2 & & 29 & \\
\hline 4 & Hoyo & 62 & & & & & & & & 0 & Precampaniforme \\
\hline 5 & Hoyo & 157 & 6 & & 10 & & 3 & & & 19 & \\
\hline 6 & Hoyo & 427 & 15 & 2 & & & & & & 17 & \\
\hline 7 & Hoyo & 522 & 1 & & & & & & & 1 & \\
\hline 8 & Hoyo & 235 & 17 & & & & & & & 17 & \\
\hline 9 & Hoyo & 678 & 154 & 2 & 99 & & & & & 255 & Precampaniforme \\
\hline 10 & Hoyo & 154 & & & & & & & & & \\
\hline 11 & Ноyо & 549 & 74 & & & & & & & 74 & \\
\hline 12 & Hoyo & 1413 & 40 & 4 & 53 & & & 1 & & 98 & Precampaniforme \\
\hline 13 & Hoyo & 392 & 104 & 3 & 99 & & & & & 206 & Precampaniforme \\
\hline 14 & Hoyo & 796 & & & & & & & & & \\
\hline 15 & Hoyo & 1766 & 193 & 10 & 25 & 1 & & & & 229 & Precampaniforme \\
\hline 16 & Hoyo & 2421 & 199 & & 11 & & & & & 210 & Precampaniforme \\
\hline 17 & Ноyо & 1589 & 7 & & & & & & & 7 & \\
\hline 18 & Hoyo & 854 & 187 & & & & & 1 & 2 & 192 & Precampaniforme \\
\hline $\begin{array}{c}19 \\
\text { (ue190) }\end{array}$ & Hoyo & 194 & 51 & & 61 & & & 1 & & 113 & Precampaniforme \\
\hline $\begin{array}{c}19 \\
\text { (ue195) }\end{array}$ & Hoyo & 1334 & 1018 & 8 & 5 & & 1 & & 6 & 1038 & Precampaniforme \\
\hline 20 & Ноyо & 1153 & 26 & & 8 & & & & & 34 & Precampaniforme \\
\hline 21 & Hoyo & 100 & 29 & & & & & & & 29 & Precampaniforme \\
\hline 22 & Hoyo & 83 & & & & & & & 10 & 10 & \\
\hline 23 & Hoyo & 452 & 216 & 7 & 25 & & & & 10 & 258 & Precampaniforme \\
\hline 24 & Hoyo & 569 & 229 & & 20 & 1 & & & 7 & 257 & Precampaniforme \\
\hline 25 & Hoyo & 318 & 14 & & 11 & & & & & 25 & Precampaniforme \\
\hline 26 & Hoyo & 274 & 1 & & & & & & & 1 & \\
\hline 28 & Hoyo & 18 & & & & & & & & & \\
\hline 29 & Hoyo & 109 & 2 & & 1 & & & & & 3 & Precampaniforme \\
\hline 30 & Hoyo & 64 & 19 & 1 & 5 & & & & & 25 & \\
\hline 31 & Hoyo & 190 & 35 & & 2 & & & & & 37 & Precampaniforme \\
\hline 32 & Ноyо & 388 & 212 & 9 & 10 & & & & 20 & 251 & Precampaniforme \\
\hline 34 & Hoyo & 39 & 6 & & & & & & & 6 & \\
\hline 35 & Hoyo & 63 & 3 & & 44 & & & & & 47 & \\
\hline 36 & Hoyo & 339 & 346 & & 2 & & & & & 348 & Precampaniforme \\
\hline 38 & Hoyo & 190 & 182 & & 19 & & & & & 201 & Precampaniforme \\
\hline 39 & Hoyo & 199 & & 1 & & & & & & 1 & \\
\hline 40 & Hoyo & 655 & 7 & & 5 & & & & & 12 & Neolítico \\
\hline 41 & Hoyo & 159 & 18 & 1 & 1 & & & 1 & & 21 & Precampaniforme \\
\hline
\end{tabular}

Tabla 1.- Cuadro sintético sobre la capacidad y contenido de los hoyos y agujeros de poste (continúa). 


\begin{tabular}{|c|c|c|c|c|c|c|c|c|c|c|c|}
\hline ID & Tipo & $\begin{array}{c}\text { Capacidad } \\
\text { (l.) }\end{array}$ & $\begin{array}{c}\text { Cerámica } \\
\text { (NR) }\end{array}$ & $\begin{array}{c}\text { Lítica } \\
\text { (NR) }\end{array}$ & $\begin{array}{c}\text { Fauna } \\
\text { (NR) }\end{array}$ & $\begin{array}{l}\text { Industria } \\
\text { ósea (NR) }\end{array}$ & Inhumaciones & Molinos & \begin{tabular}{|c|} 
Manteado \\
de barro
\end{tabular} & Total & Atribución \\
\hline 42 & Hoyo & 265 & 1290 & 22 & 234 & 2 & & 6 & 25 & 1579 & Precampaniforme \\
\hline 43 & Hoyo & 78 & & & & & & & & & \\
\hline 44 & Hoyo & 395 & & & 1 & & & & & 1 & \\
\hline 45 & Hoyo & 25 & 4 & & & & & & & 4 & \\
\hline 46 & Hoyo & 40 & 3 & & & & & & & 3 & \\
\hline 47 & Hoyo & 26 & 1 & & & & & & & 1 & \\
\hline 48 & Hoyo & 77 & 6 & & 1 & & & & & 7 & Precampaniforme \\
\hline 49 & Hoyo & 125 & 9 & 1 & & & & & & 10 & Neolítico \\
\hline 51 & Hoyo & 45 & 15 & 4 & & & & & & 19 & Neolítico \\
\hline 52 & Hoyo & 7 & & & & & & & & & \\
\hline 53 & Hoyo & 22 & 2 & & & & & & & 2 & \\
\hline 54 & Hoyo & 50 & 13 & & 2 & & & & & 15 & Precampaniforme \\
\hline 56 & Hoyo & 55 & 20 & & & & & & & 20 & \\
\hline 57 & Hoyo & 53 & & & & & & & & & \\
\hline 58 & Hoyo & 38 & 18 & & & & & & & 18 & \\
\hline 60 & Hoyo & 549 & 94 & 3 & 12 & & & & & 109 & Neolítico \\
\hline 61 & Hoyo & 471 & 5 & 2 & 2 & & & & & 9 & \\
\hline 62 & Hoyo & 141 & & & & 8 & 1 & & & 9 & Neolítico \\
\hline 63 & Ноуо & 28 & & & & & & & & & \\
\hline 64 & Hoyo & 20 & & & & & & & & & \\
\hline 66 & Ноуо & 235 & 29 & 1 & 5 & & & & & 35 & \\
\hline 67 & Hoyo & 75 & 42 & 2 & 11 & & & & & 55 & Precampaniforme \\
\hline 68 & Hoyo & 204 & 50 & 4 & 11 & & & & & 65 & Precampaniforme \\
\hline 69 & Hoyo & 58 & 3 & 1 & & & & & & 4 & \\
\hline 70 & Ноyo & 132 & 5 & 3 & 1 & & & & & 9 & \\
\hline 71 & Hoyo & 36 & 5 & & 1 & & & & & 6 & \\
\hline 72 & Hoyo & 41 & & & & & & & & & \\
\hline 73 & Hoyo & 89 & 2 & 1 & & & & & & 3 & \\
\hline 74 & Hoyo & 140 & 27 & 1 & 13 & & & & & 41 & \\
\hline 75 & Hoyo & 33 & 17 & 11 & & & & & & 28 & Neolítico \\
\hline 76 & Hoyo & 9 & & & & & & & & & \\
\hline 77 & Ноyо & 51 & 6 & 2 & & & & & & 8 & \\
\hline 78 & $\begin{array}{l}\text { Agujero } \\
\text { de poste }\end{array}$ & 14 & & & & & & & & & \\
\hline 79 & $\begin{array}{l}\text { Agujero } \\
\text { de poste }\end{array}$ & 10 & & & & & & & & & \\
\hline 80 & $\begin{array}{l}\text { Agujero } \\
\text { de poste }\end{array}$ & 5 & & & & & & & & & \\
\hline
\end{tabular}

Tabla 1.- Cuadro sintético sobre la capacidad y contenido de los hoyos y agujeros de poste (viene de atrás y continúa). 


\begin{tabular}{|l|c|c|c|c|c|c|c|c|c|c|c|}
\hline ID & Tipo & $\begin{array}{c}\text { Capacidad } \\
\text { (l.) }\end{array}$ & $\begin{array}{c}\text { Cerámica } \\
\text { (NR) }\end{array}$ & $\begin{array}{c}\text { (ítica } \\
\text { (NR) }\end{array}$ & $\begin{array}{c}\text { Fauna } \\
\text { (NR) }\end{array}$ & $\begin{array}{l}\text { Industria } \\
\text { ósea (NR) }\end{array}$ & Inhumaciones & Molinos & $\begin{array}{c}\text { Manteado } \\
\text { de barro }\end{array}$ & Total & Atribución \\
\hline 81 & $\begin{array}{r}\text { Agujero } \\
\text { de poste }\end{array}$ & 11 & & & & & & & & & \\
\hline 82 & $\begin{array}{r}\text { Agujero } \\
\text { de poste }\end{array}$ & 8 & & & & & & & & & \\
\hline 83 & $\begin{array}{c}\text { Agujero } \\
\text { de poste }\end{array}$ & 3 & & & & & & & & & \\
\hline 84 & $\begin{array}{c}\text { Agujero } \\
\text { de poste }\end{array}$ & 3 & & & & & & & & & \\
\hline 85 & $\begin{array}{l}\text { Agujero } \\
\text { de poste }\end{array}$ & 11 & & & & & & & & & \\
\hline 86 & $\begin{array}{l}\text { Agujero } \\
\text { de poste }\end{array}$ & 4 & & & & & & & & & \\
\hline 87 & $\begin{array}{l}\text { Agujero } \\
\text { de poste }\end{array}$ & 6 & & & & & & & & & \\
\hline 8 & $\begin{array}{c}\text { Agujero } \\
\text { de poste }\end{array}$ & 2 & & & & & & & & & \\
\hline 89 & $\begin{array}{l}\text { Agujer } \\
\text { de poste }\end{array}$ & 3 & & & & & & & & & \\
\hline 90 & $\begin{array}{l}\text { Agujer } \\
\text { de poste }\end{array}$ & 1 & & & & & & & & & \\
\hline
\end{tabular}

Tabla 1.- Cuadro sintético sobre la capacidad y contenido de los hoyos y agujeros de poste (viene de atrás).

pientes se cocieron en un entorno donde la atmósfera no estaba controlada, seguramente a través de la técnica "cocción a fuego abierto".

Otro de los aspectos técnicos a destacar es la naturaleza de las inclusiones y su tipometría. En este sentido, el rasgo destacado es el uso de desgrasantes de calibre fino, ya sea de modo individual (38\%) o mezclado con otros de tamaño medio $(20 \%)$, grueso $(5 \%)$ o medio y grueso $(12 \%)$. Por lo tanto, las pastas muestran un aspecto tosco, motivado por la variabilidad tipométrica de las inclusiones y su irregular distribución en las pasta. Este rasgo demuestra el carácter intencional de buena parte de estos elementos. Entre ellos predomina el uso del cuarzo (63\%) sobre otros materiales, ya sean inorgánicos -arenas cuarcíticas, caliza, mica, chamota- u orgánicos -restos vegetales-.

En lo referente al tratamiento de superficies, predomina el alisado $(43,8 \%$ en las paredes exteriores y $51,5 \%$ en las interiores), seguido del bruñido $(20,5 \%$ de los exteriores y $7,6 \%$ de los interiores). La técnica del espatulado y del engobado es meramente testimonial $(2,7 \%$ y $0,9 \%$, respectivamente). Como grupo distinto destaca un conjunto de recipientes (casi el 12\% de la muestra) con un acabado "rugoso", producto tanto de la elevada cantidad de arenas en la pasta como de una factura aparentemente poco cuidada que deja a la vista evidencias de su fabricación (dedadas, huellas de urdido, uniones de placas, bordes muy irregulares, formas sinuosas etc.). Finalmente, llama la atención el elevado porcentaje ( $20 \%$ en la cara externa y $27,1 \%$ en la cara interna) de la muestra en las que el acabado no se ha podido consignar. La explicación se encuentra en el estado de conservación de las piezas, con un alto número de fragmentos afectados por el contexto ácido del entorno geológico (fracturas laminares y concreciones).

En cuanto a las formas, se puede señalar que en general se trata de recipientes de morfología simple, tendentes a la esfera, donde predominan las formas cerradas, de paredes hondas y bases planas (Fig. 7). Entre la vajilla destacan los cuencos de perfil esférico y globular, junto a las cazuelas de perfil también globular y los vasos ovoides. Además, están representados, aunque en menor medida, las orzas de almacenaje de perfil cilíndrico y las ollas de cocina de perfil globular. El conjunto lo completa alguna escudilla. Incidiendo de nuevo sobre el particular grupo de cerámica de "acabado rugoso" hay que destacar su vinculación con una forma igualmente peculiar de Fuente Celada como son los vasos troncocónicos (A10), de paredes esbeltas y tamaño mediano. 


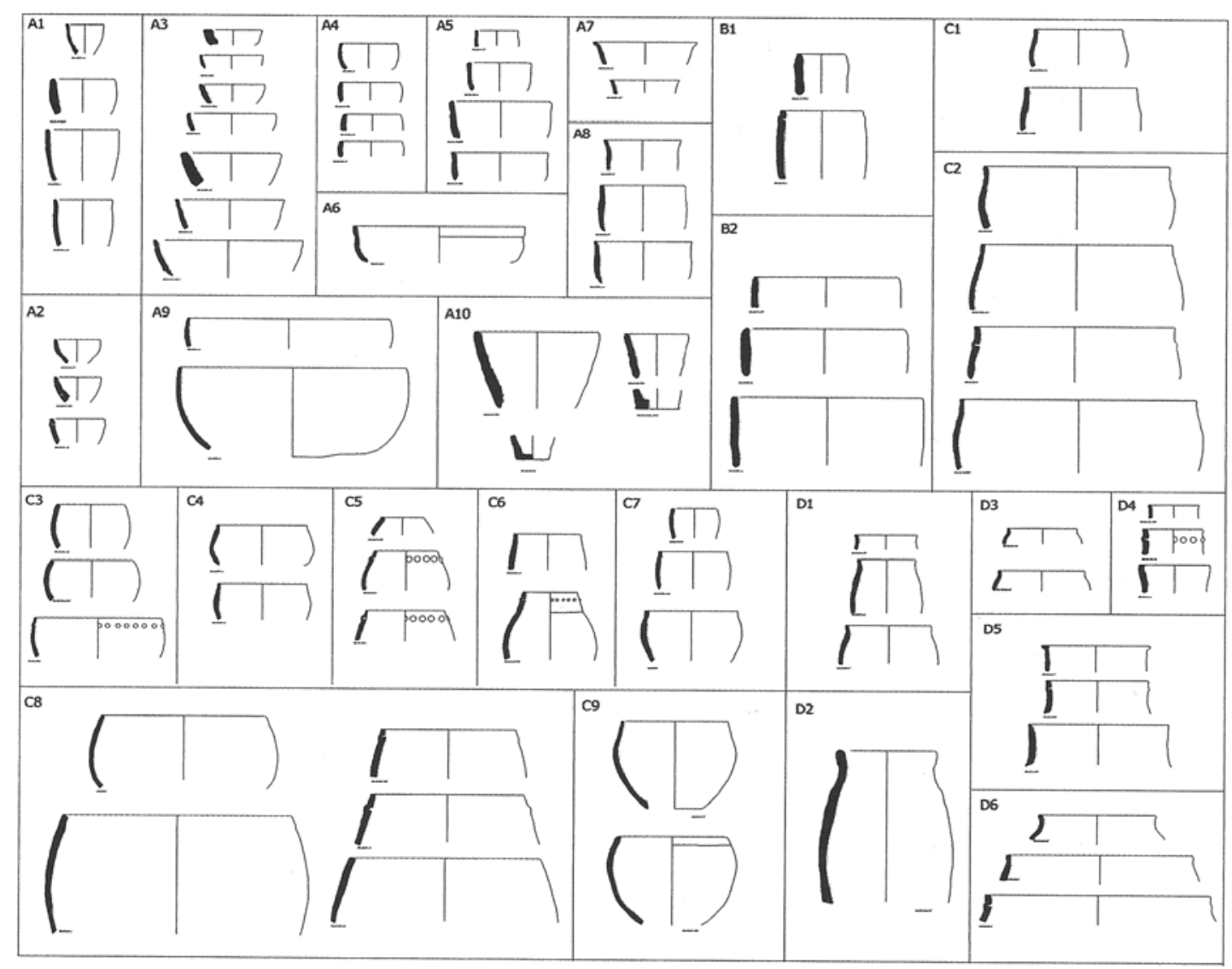

Figura 7.- Tabla de formas cerámicas de Fuente Celada.

Al margen de estos aspectos técnicos más o menos comunes, se han documentado dos tradiciones alfareras distintas. Una de las producciones, minoritaria, aparece focalizada en el sector norte del área excavada (estructuras 40, 49, 51, 70 y 75) y cuenta con una serie de rasgos particulares, tales como pastas de aspecto harinoso, superficies engobadas y atributos decorativos singulares (Fig. 8) que permiten determinar su adscripción al Neolítico: motivos formados por acanaladuras -ya sea en forma de bandas paralelas o rellenando motivos colgantes trazados también con una acanaladura-, mamelones o líneas en "Boquique neolítico" (Arnaiz Alonso 2005, Estremera Portela 2003, Fabián García 2006, Municio González 1988, Ortega et al. 2008, Verges et al. 2008, Rojo Guerra et al. 2008a, Rojo Guerra et al. 2008b). Tanto los atributos de las piezas como la ubicación del yacimiento se encuentran en sintonía con el cercano yacimiento de Altotero de Modúbar (Arnaiz Alonso y Esparza Arroyo 1985).
La segunda de las producciones fonteceladeñas, presente en la mayor parte de las estructuras negativas que integran el yacimiento, se reconoce en vasos de pastas hojaldradas, decorados con motivos característicos del Calcolítico precampaniforme (Fig. 8): líneas simples o acanaladas bajo el borde, pastillas repujadas y triángulos rellenos de puntos, ya sean simples o formando motivos quebrados, conocidos en un buen número de yacimientos de esta época (Álvarez Clavijo et al. 1996; Apellaniz 1974; Apellaniz y Domingo 1987; Delibes de Castro et al. 1995; Delibes de Castro y Herrán Martínez 2007; Domínguez Bolaños 1991; Fabián García 2006; García Barrios 2007; Gutiérrez Palacios 1962; Herrán Martínez 1986; Herrán Martínez 1995; Herrán Martínez y Santiago Pardo 1989; Hurtado Pérez 1982; López Plaza y Piñel 1978; Pérez Rodríguez et al. 1990; Pérez Rodríguez et al. 1991; Priego y Quero 1992; Val Recio 1992; Val Recio y Herrán Martínez 1994; Valiente Malla 1996). Comentario aparte 

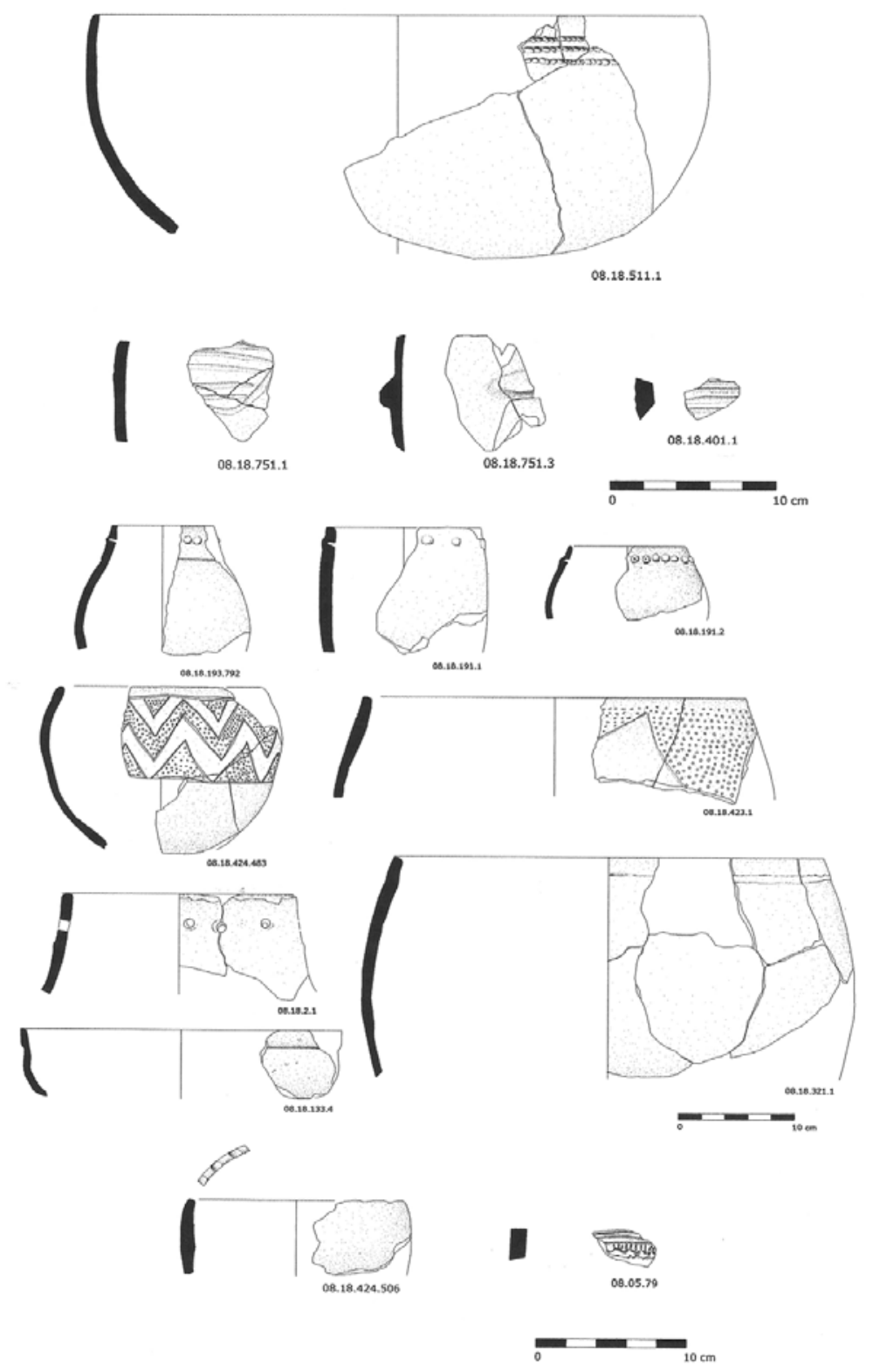

Figura 8.-Piezas representativas de las decoraciones cerámicas documentadas en Fuente Celada.

merecen otros motivos ornamentales menos significativos pero asociados a contextos de atribución calcolítica en Fuente Celada. Por un lado, un conjunto de piezas que se reconocen por una característica moldura, sola o asociada a otros elementos decorativos como líneas incisas horizontales o pastillas repujadas, que decora el borde. Por otro lado tenemos las digitaciones, en el caso particular de Fuente Celada siempre vinculadas a los recipientes de acabado "rugoso".

\subsection{Industria lítica}

El conjunto de industria lítica recuperado está compuesto por lascas simples $(58 \%)$, restos de talla $(28 \%)$, una reducida representación de láminas $(9 \%)$ y dos bases de explotación directa (5\%). Tan sólo hay tres piezas con transformación secundaria: una pequeña punta de flecha con pedúnculo realizada sobre lámina de sílex (Fig. 9), un pequeño raspador sobre lasca de sílex y un fragmento de 
lámina, también en sílex, con retoque plano, invasor, alterno y discontinuo. La materia prima predominante es el sílex (96\%), resultando marginal la utilización de otros soportes, tales como la caliza, la cuarcita o el cuarzo. Esta proporción no resulta extraña si tenemos en cuenta que el sílex está presente en el entorno de Fuente Celada: sobre toda la plataforma del páramo terciario pueden encontrarse abundantes nódulos, por lo que se podría asegurar el origen autóctono de gran parte de este repertorio lítico.

La reducida presencia de industria lítica en el yacimiento (110 piezas en 195 unidades estratigráficas) sugiere que la gestión principal se realizaba fuera del mismo. El análisis de las fases de producción lítica (Fig. 10) parece indicar que los núcleos llegaban mayoritariamente conformados al yacimiento. Este tipo de gestión se reconoce en contextos calcolíticos similares a Fuente Celada (Gutiérrez Sáez 1998: 208, López López 2005: 314, Carmona Ballestero 2010: 129). Sin embargo, debemos recalcar la aparente marginalidad de la talla entre las actividades desarrolladas en el lugar, por lo que no descartamos que la baja presencia de elementos líticos esté en relación con la formación del registro; es decir, que su presencia en los depósitos de relleno se explicaría como productos de

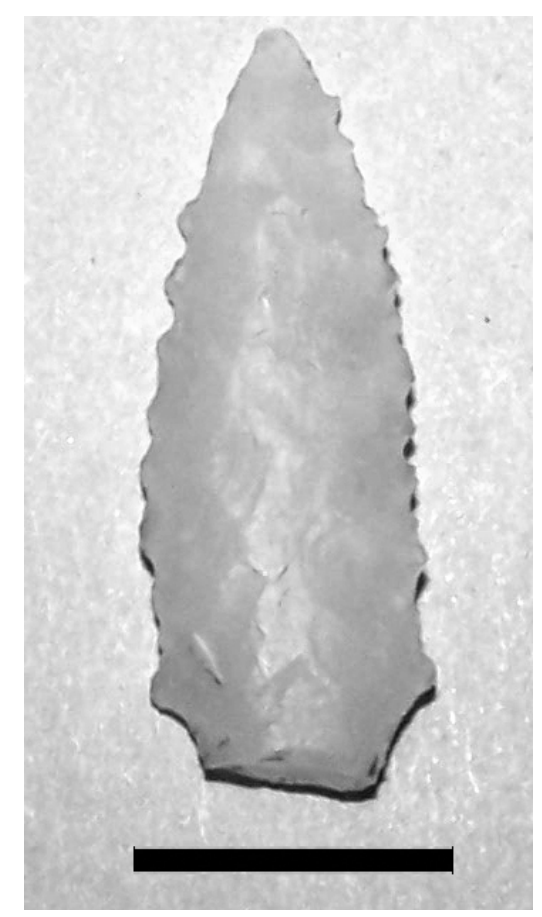

Figura 9.- Punta de flecha pedunculada (escala: $1 \mathrm{~cm})$.

Complutum, 2011, Vol. 22 (1): 47-69 desecho. No debemos olvidar que únicamente se ha excavado un porcentaje limitado del yacimiento, por lo que las particulares características de la muestra también podrían estar relacionadas con una presumible estructuración del espacio en diferentes áreas de producción y reproducción social.

\subsection{Industria ósea}

La colección está compuesta por siete piezas, las cuáles podríamos dividir en dos grupos funcionales: las herramientas en hueso y en asta y los objetos de adorno personal. Dentro del grupo de las "herramientas" se han recuperado dos espátulas (Fig. 11), una de ellas elaborada sobre un metápodo de ovicáprido, y dos punzones. El segundo conjunto (Fig. 12), está representado por tres aros de hueso (20 y $16 \mathrm{~mm}$ de diámetro) descubiertos alrededor del cuello de un individuo masculino senil en la inhumación depositada en la estructura negativa 62. En primera instancia, la presencia de estos elementos remite a cronologías neolíticas, tal y como apunta el estudio de los anillos de hueso de Casa Montero en Madrid (Yravedra Sainz de los Terreros et al. 2008). Como se verá, la datación absoluta obtenida del inhumado corrobora tal inferencia.

\subsection{Restos constructivos}

$\mathrm{Al}$ igual que en otros muchos yacimientos de la Submeseta Norte, en Fuente Celada no se cuenta con evidencias directas de estructuras de hábitat. Sin embargo, la presencia de restos de manteado de barro en algunos hoyos, algo habitual en yacimientos calcolíticos de la Meseta (Blasco et al. 1994: 55, Palomino Lázaro et al. 1997: 72, García

Fase de producto

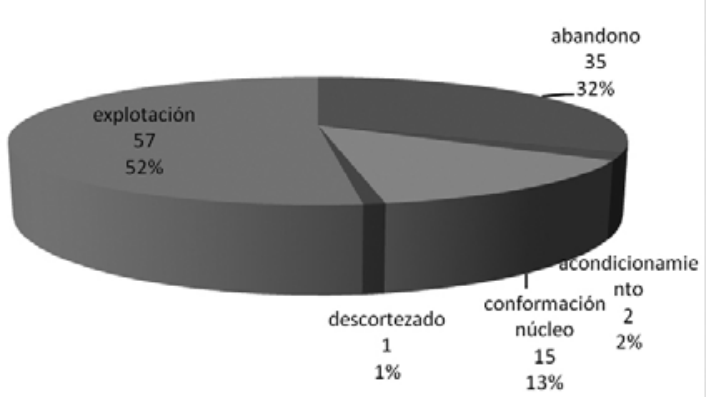

Figura 10.- Frecuencias y porcentajes del material lítico en relación a las fases de producción documentadas. 
Barrios 2004-2005: 61-62, 2007: 275-281, Fabián García 2006, Pérez Rodríguez et al. 1991, Delibes de Castro et al. 1997), puede considerarse un indicio de la existencia de cabañas, si consideramos que estos materiales servirían para el revestimiento de sus paredes.

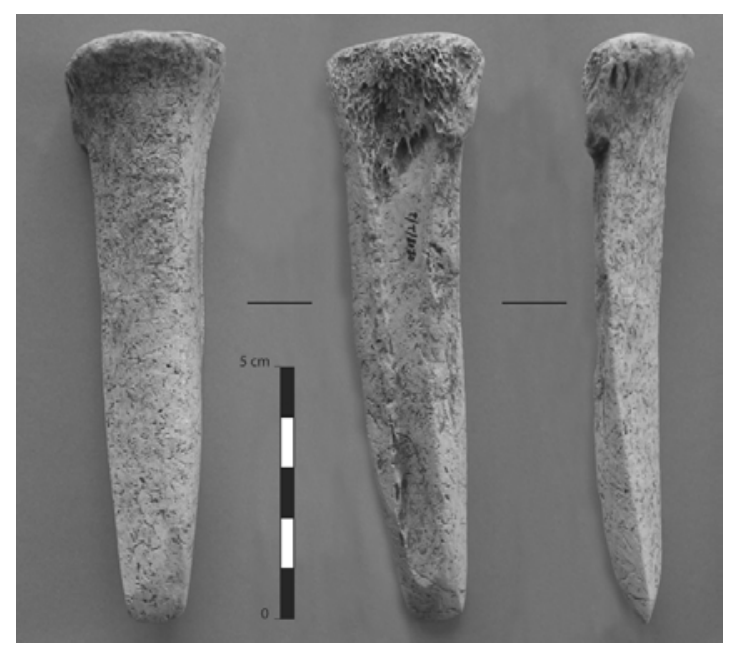

Figura 11.- Espátula sobre metápodo de ovicáprido.

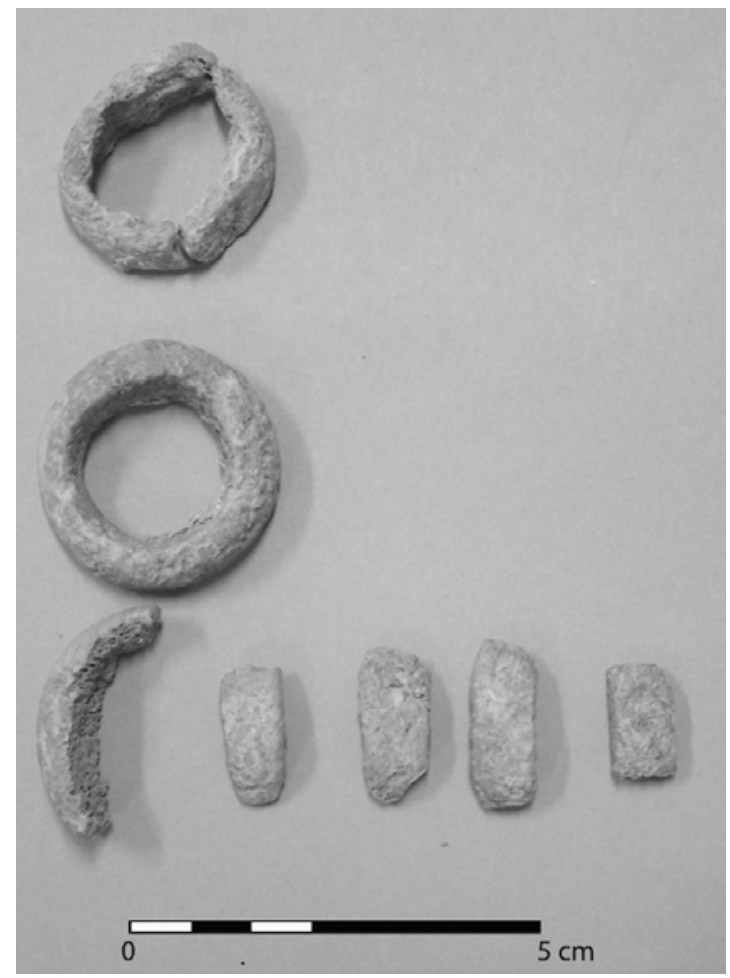

Figura 12.- Aros de hueso recuperados en el hoyo 62.
Desde nuestro punto de vista, la presencia de este tipo de evidencias se ha minusvalorado, entre otras cosas porque en muchas ocasiones no se considera significativo al carecer de información relevante desde el punto de vista tipológico. Estos restos remiten a un tipo de construcción con bastante arraigo y vigencia temporal en la Meseta: cabañas circulares construidas a base de postes y entramado vegetal recubierto de barro. Frente a la supuesta fragilidad de estas construcciones, la Arqueología Experimental ha demostrado que este tipo de estructuras tiene tres cualidades básicas: simplicidad constructiva, solidez y durabilidad (García Barrios 2004-2005: 66), que se alejan de la idea de provisionalidad que suele asociarse a este tipo de cabañas.

\subsection{Restos faunísticos}

Sólo la mitad de las estructuras excavadas han proporcionado algún tipo de vestigios de esta clase. Así, tenemos que se ha recuperado un total de 448 piezas en 30 hoyos, muchas de ellas fragmentadas o degradadas debido a procesos postdeposicionales como erosiones radiculares y afecciones químicas, fruto del entorno geológico, $u$ otras alteraciones de origen antrópico, como huellas de combustión o corte.

Los datos manejados, pendientes aún de análisis definitivo, muestran la presencia de las especies animales más habituales en este tipo de estaciones arqueológicas (Morales Muñiz 1992; Morales Muñiz y Liesau 1994; Díaz del Río 2001: 44; Fabián García 2006: 453), con una cabaña ganadera formada por las tres especies básicas a las que se suma el aprovechamiento de especies salvajes a través de la caza (uro, cérvidos y ¿caballo?). Como elemento significativo cabe señalar la aparición de partes de la columna vertebral de tres ejemplares distintos de bóvidos en conexión anatómica (hoyos 9, 12 y 13). En el hoyo 9 se conservaba, incluso, parte del cráneo y las astas del animal.

Un comentario aparte merece la presencia de cánidos. En apariencia no es una especie cuya cría produzca rendimientos económicos directos, pero su presencia es algo habitual en el registro calcolítico (García Barrios 2007: 407-417, Díaz del Río 2001: 44, Fabián García 2006: 453). Normalmente, su cría se suele relacionar con labores de guarda, ganadería y caza. En algunos casos han sido utilizados con motivos ideológicos (ver p.ej. Liesau et 
al. 2008). En Fuente Celada no está clara la manipulación ideológica de los canes aunque, eso sí, su presencia en los depósitos se ciñe normalmente a cráneos o partes de los mismos.

\subsection{Elementos de molienda-triturado}

Además de los vestigios descritos, se han recuperado restos de molinos barquiformes (hoyos 19, 32,41 y 42) y muelas de mano (hoyos 3, 12 y 18). Es curiosa la disociación de manos y bases (no han aparecido juntas ambas piezas), lo cual puede ser tomado como un indicio de que llegaron a los hoyos en forma de desecho, una vez acabada su vida útil. A pesar de ser tratados normalmente como un elemento secundario en los estudios arqueológicos, se puede considerar que estos materiales forman parte del conjunto de objetos exóticos que circulan por las redes de intercambio (Blasco et al. 2007-2008). La razón es que la mayoría se fabrican en materias primas ajenas a los entornos inmediatos de los yacimientos. Sin embargo, en Fuente Celada las materias primas empleadas no son ajenas al entorno geológico, en este caso vinculadas a los materiales cuaternarios de los valles. Sí parece haber existido una selección, con una preferencia por la arenisca. Una faceta interesante es la concentración de hallazgos en la zona sur, en el mismo espacio en el que se concentran los hallazgos de manteado de barro.

\subsection{Inhumaciones}

El registro arqueológico documentado en Fuente celada incorpora tres contextos funerarios, todos ellos con morfología de inhumación en fosa (Fig. 13). El primero de ellos, localizado en el extremo norte del yacimiento, apareció en una cubeta (Hoyo 62; Hecho XLIX), de $85 \mathrm{~cm}$ de diámetro máximo y una profundidad conservada de $23 \mathrm{~cm}$, que contenía los restos de un individuo adulto colocado en posición fetal. Esta disposición del cadáver es habitual en un buen número de yacimientos meseteños (Fabián García, 1995, Bellido Blanco, 1996, Díaz del Río et al., 1997, Blasco Bosqued et al., 2005, Fabián García, 2006, Liesau et al., 2008, Esparza et al. 2008). Este individuo portaba tres aros de hueso en torno al cuello, formando lo que parece ser un collar.

El segundo se localiza en el Hoyo 19, el cual presentaba una secuencia formada por dos hechos estratigráficos: una fosa y su relleno (Hecho XLII) que aparecen cortados por un hoyo más moderno (Hecho XLIII). Éste último presenta una morfología de tendencia globular con un diámetro en su boca de $80 \mathrm{~cm}$ y una altura de $130 \mathrm{~cm}$. Entre los rellenos que lo colmataron se documentaron los restos esqueléticos de una mujer joven. Lo curioso de esta inhumación es la disposición del esqueleto: boca abajo, casi vertical, cuyo único parangón lo encontramos en el yacimiento madrileño de Las Matillas, en este caso asociado a un depósito secundario de los restos (Díaz del Río et al. 1997: 104). Los restos óseos estaban en conexión anatómica, aunque la cabeza apareció algo separada del cuerpo, debido a la inclinación del cadáver y a la acción de la gravedad.

Curiosamente, en esta fosa se concentra una de las mayores acumulaciones de material cerámico del yacimiento: 1018 fragmentos, lo que supone el 19,5\% del total (Martínez Díez et al. 2008). Asimismo, en este mismo contexto se han documentado los únicos restos de équido y de suido de Fuente Celada; y, una última peculiaridad, en el fondo de la misma estructura se encontró un fémur de cánido. La cantidad de particularidades que ofrece este conjunto son excesivas para deberse exclusivamente al azar, de ahí que debamos plantearnos vías interpretativas que enlazan con la ritualización de la muerte, pues las evidencias remiten a un contexto de utilización ideológica del deceso. ¿En qué sentido? Aún no estamos en disposición de responder con garantías a esta cuestión, pero es apreciable que ha existido un consumo diferencial: un dispendio vinculado a esta inhumación. En este caso, los bienes no parecen amortizarse como ajuar y ofrenda. Más bien, la acumulación de restos puede encajar con la realización de algún tipo de festival vinculado al deceso, práctica habitual en las organizaciones sociales parentales (Dietler 1995; Hayden 1995).

Finalmente, dentro de una fosa de planta circular de $115 \mathrm{~cm}$ de diámetro, de sección cuenquiforme y una profundidad de $20 \mathrm{~cm}$ (Hoyo 5), aparecieron los restos parciales e inconexos de tres individuos: un subadulto y dos hombres adultos. La selección de piezas anatómicas y la falta de conexión entre ellas permiten inferir que estos restos se depositaron en la fosa cuando la descomposición de los cadáveres era muy avanzada. Algo habitual también en los contextos funerarios en fosa de la Meseta. 


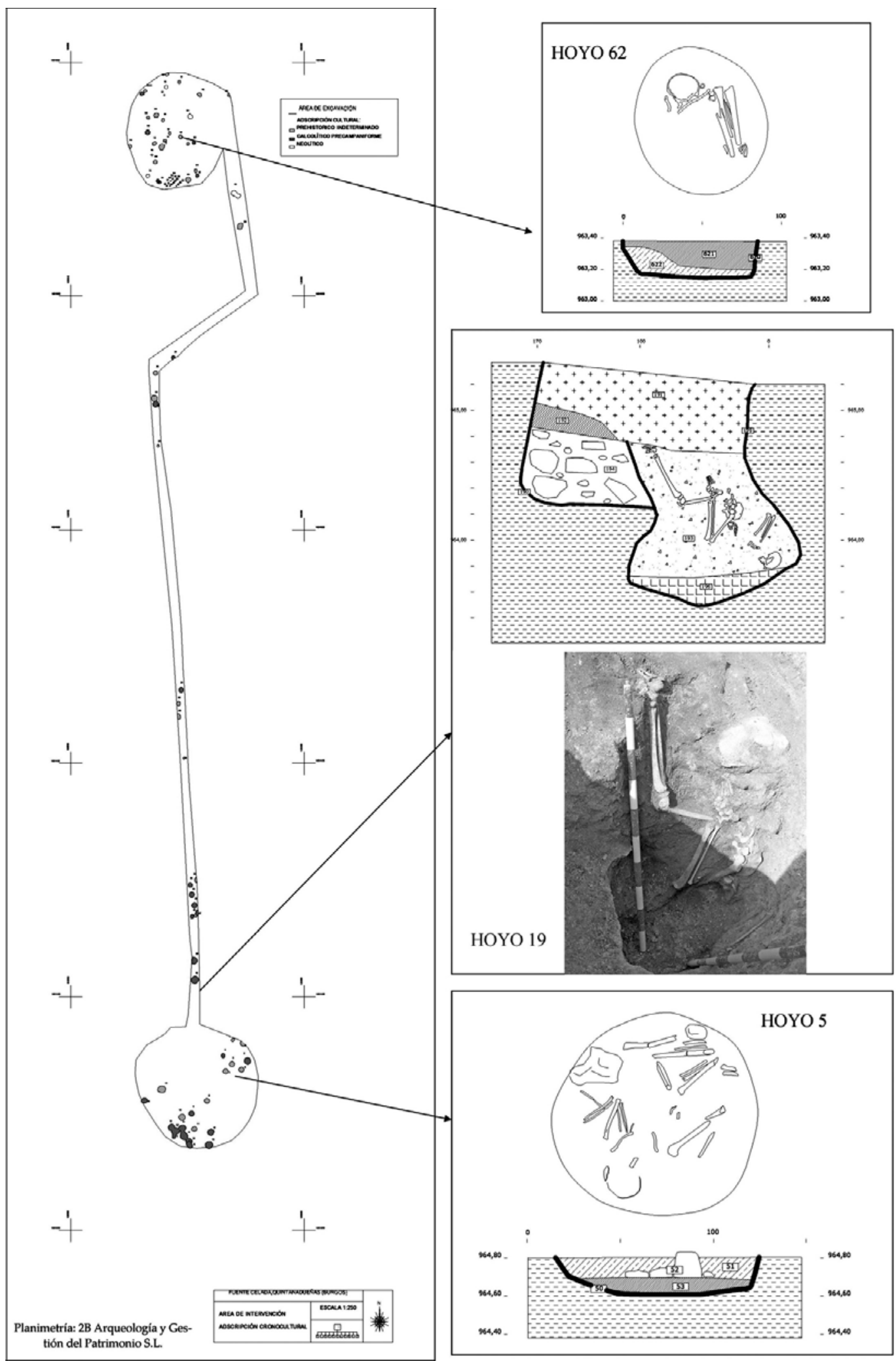

Figura 13.- Localización, plantas y secciones de las inhumaciones documentadas. 
La muestra de individuos recuperados (Gutierrez-Avellanosa 2008) carece de significación estadística para definir al conjunto de la población, entre otras cosas porque casi con toda seguridad no sean representativos más que de una fracción de la comunidad. No obstante, esto no es óbice para poder reseñar ciertos aspectos interesantes (Tabla 2). Si comparamos los datos con otras poblaciones arqueológicas de momentos similares (Etxeberría en Fabián García 1995: 4558, Díaz del Río et al. 1997, Martínez en Ródanes Vicente 1999, Fabián García 2006), encontramos similitudes interesantes. En primer lugar, la estatura cumple con los cánones de la época: individuos masculinos con valores que rondan los 155-160 $\mathrm{cm}$ e individuos femeninos cuya talla es algo menor, en torno a 145-150 cm. En segundo lugar, es habitual encontrar individuos con muestras de estados carenciales en la alimentación (Campillo 2001: 284-286), como evidencia en nuestro caso la criba orbitalia de la mujer del hoyo 19. En este mismo sentido se manifiesta Fabián respecto de las poblaciones del Valle del Amblés -Cerro de la Cabeza, Aldeagordillo, El Tomillar- con un buen número de individuos con esta misma patología (Fabián García 2006: 438).

Otro rasgo que presentan los individuos de Fuente Celada son las excrecencias óseas observadas en la mayor parte de los casos en los huesos de las extremidades superiores, más concretamente en sus carillas articulares, que indican sobreesfuerzos continuos en la actividad física diaria. A su vez, y derivado de esto, se documenta en ciertas regiones anatómicas un ligero grado de torsión en las diáfisis (Gutierrez-Avellanosa 2008).

\section{Dataciones Radiocarbónicas}

Se tomaron 8 muestras para su datación a través de espectrometría del acelerador de partículas (AMS). Las muestras fueron enviadas al Center for Applied Isotope Studies (CAIS) de la Universidad de Georgia (EE.UU.), y sus resultados, después de la calibración con el programa Oxcal 4.1 (Bronk Ramsey 2009, 2010, Reimer et al. 2009), se recogen en la tabla 3.

Todas las dataciones absolutas obtenidas, a excepción de la identificada como UGA-7565, se ciñen al marco temporal en el que se reconocen las manifestaciones arqueológicas vinculadas al Calcolítico en la Meseta Central (3300-1900 cal BC) (Castro et al. 1996, Estremera Portela 2003, Fabián García 2006). En este marco se reconocen dos fases diferenciadas, una fase temprana denominada comúnmente Precampaniforme (33002400 cal BC) y una fase final Campaniforme (2600-1900 cal BC). En este sentido, las dataciones obtenidas reflejan esta dualidad, pero con matices. La mayoría de las dataciones realizadas en contextos donde las piezas determinan una atribución precampaniforme se circunscriben a la primera mitad del III milenio, en concreto dentro de una horquilla temporal que oscila entre el 2900 al 2500 cal BC.

Una excepción es la fecha obtenida en el hoyo 60 , que se adentra considerablemente en el rango comprendido entre el 2400 al 2100; es decir, dentro del periodo de vigencia del Calcolítico asociado con el Campaniforme. El conjunto cerámico procedente del contexto donde se recuperó la muestra no es muy expresivo, aunque se recono-

\begin{tabular}{|c|c|c|c|c|c|c|}
\hline Individuo & Estado & Hoyo & Sexo & Edad & Altura & Patologías \\
\hline Esqueleto 1 & Parcial & 5 & $?$ & Subadulto & $?$ & \\
\hline Esqueleto 2 & Completo & 5 & $\mathrm{M}$ & Adulto & $154-156 \mathrm{~cm}$ & \\
\hline Esqueleto 3 & Completo & 5 & M & $35-40$ & $152-156 \mathrm{~cm}$ & Desgaste dental \\
\hline Esqueleto 4 & Completo & 19 & $\mathrm{~F}$ & $19-22$ & $143-146 \mathrm{~cm}$ & Criba Orbitalia \\
\hline \multirow{4}{*}{ Esqueleto 5} & \multirow{4}{*}{ Completo } & \multirow{4}{*}{62} & \multirow{4}{*}{ M } & \multirow{4}{*}{ Adulto viejo } & \multirow{4}{*}{$160-161 \mathrm{~cm}$} & $\begin{array}{l}\text { Reabsorción } \\
\text { alveolar }\end{array}$ \\
\hline & & & & & & Osteofitosis \\
\hline & & & & & & Artrosis \\
\hline & & & & & & Osteoporosis \\
\hline
\end{tabular}

Tabla 2.- Síntesis de los datos ofrecidos por el estudio antropológico de los restos inhumados. 


\begin{tabular}{|c|c|c|c|c|c|c|c|}
\hline Yacimiento & ID & Fecha B.P. & Calibración $2 \sigma$ & $\delta 13 C$ & Material & Contexto & Atribución \\
\hline \multirow{3}{*}{$\begin{array}{l}\text { Fuente } \\
\text { Celada }\end{array}$} & \multirow{3}{*}{ UGA-7565 } & \multirow{3}{*}{$6120 \pm 30$} & $5208(23.4 \%) 5144$ & \multirow{3}{*}{$-19.5 \%$} & \multirow{3}{*}{$\begin{array}{l}\text { Hueso } \\
\text { humano }\end{array}$} & \multirow{3}{*}{ H62, UE 622} & \multirow{3}{*}{ Neolítico } \\
\hline & & & $5139(9.4 \%) 5091$ & & & & \\
\hline & & & $5083(62.6 \%) 4961$ & & & & \\
\hline \multirow{4}{*}{$\begin{array}{l}\text { Fuente } \\
\text { Celada }\end{array}$} & \multirow{4}{*}{ UGA-7563 } & \multirow{4}{*}{$4200 \pm 25$} & $2893(27.5 \%) 2850$ & \multirow{4}{*}{$-21.0 \%$} & \multirow{4}{*}{$\begin{array}{l}\text { Hueso } \\
\text { fauna }\end{array}$} & \multirow{4}{*}{ H42; UE 424} & \multirow{4}{*}{ Precampaniforme } \\
\hline & & & $2814(52.9 \%) 2741$ & & & & \\
\hline & & & $2729(14.4 \%) 2694$ & & & & \\
\hline & & & $2687(0.7 \%) 2680$ & & & & \\
\hline \multirow{3}{*}{$\begin{array}{l}\text { Fuente } \\
\text { Celada }\end{array}$} & \multirow{3}{*}{ UGA-7561 } & \multirow{3}{*}{$4170 \pm 25$} & $2880(19.8 \%) 2835$ & \multirow{3}{*}{$-20.7 \%$} & \multirow{3}{*}{$\begin{array}{l}\text { Hueso } \\
\text { fauna }\end{array}$} & \multirow{3}{*}{ H15; UE 152} & \multirow{3}{*}{ Precampaniforme } \\
\hline & & & $2817(75.1 \%) 2667$ & & & & \\
\hline & & & $2643(0.5 \%) 2640$ & & & & \\
\hline \multirow{3}{*}{$\begin{array}{l}\text { Fuente } \\
\text { Celada }\end{array}$} & \multirow{3}{*}{ UGA-7559 } & \multirow{3}{*}{$4100 \pm 25$} & $2860(22.1 \%) 2809$ & \multirow{3}{*}{$-19.2 \%$} & \multirow{3}{*}{$\begin{array}{l}\text { Hueso } \\
\text { humano }\end{array}$} & \multirow{3}{*}{$\begin{array}{l}\text { H5; UE 53, } \\
\text { indiv } 2\end{array}$} & \multirow{3}{*}{ Precampaniforme } \\
\hline & & & $2752(8.0 \%) 2721$ & & & & \\
\hline & & & $2702(65.3 \%) 2574$ & & & & \\
\hline \multirow{3}{*}{$\begin{array}{l}\text { Fuente } \\
\text { Celada }\end{array}$} & \multirow{3}{*}{ UGA-7562 } & \multirow{3}{*}{$4100 \pm 25$} & $2860(22.1 \%) 2809$ & \multirow{3}{*}{$-19.2 \%$} & \multirow{3}{*}{$\begin{array}{l}\text { Hueso } \\
\text { humano }\end{array}$} & \multirow{3}{*}{ H19; UE 193} & \multirow{3}{*}{ Precampaniforme } \\
\hline & & & $2752(8.0 \%) 2721$ & & & & \\
\hline & & & $2702(65.3 \%) 2574$ & & & & \\
\hline $\begin{array}{l}\text { Fuente } \\
\text { Celada }\end{array}$ & UGA-7560 & $4030 \pm 25$ & $2620(95.4 \%) 2474$ & $-19.0 \%$ & $\begin{array}{l}\text { Hueso } \\
\text { humano }\end{array}$ & $\begin{array}{c}\text { H5; UE 53, } \\
\text { indiv. } 3\end{array}$ & Precampaniforme \\
\hline $\begin{array}{l}\text { Fuente } \\
\text { Celada }\end{array}$ & UGA-7564 & $3790 \pm 25$ & $2292(95.4 \%) 2140$ & $-20.6 \%$ & $\begin{array}{l}\text { Hueso } \\
\text { fauna }\end{array}$ & H60; UE 601 & Precampaniforme \\
\hline
\end{tabular}

Tabla 3.- Dataciones radiocarbónicas obtenidas en Fuente Celada.

cen perforaciones, acanaladuras y algún mamelón. Esta datación, no obstante, concuerda con una evidencia indirecta: un fragmento de campaniforme ciempozuelos recuperado en uno de los sondeos, el $\mathrm{X}$, que se ubica en el sector norte del yacimiento (Pascual Blanco y Martínez Díez 2008). En este sentido, los tipos y formas del hoyo 60 concuerdan con las piezas lisas que acompañan a las piezas campaniformes en determinados contextos domésticos (Carmona Ballestero 2010: 103; Garrido Pena 2000).

Como ya se ha señalado, la muestra UGA-7565 ha deparado una datación neolítica para el enterramiento del hoyo 62, algo que concuerda con el conjunto de piezas de esa atribución recuperadas en el sector norte de la excavación (Fig. 14).

Dejando al margen la primera fase neolítica, el rango cronológico con más determinaciones es el correspondiente a 2900-2475 cal BC. Parece que la vigencia del yacimiento se ciñe precisamente a esta primera mitad del III milenio y que se llega a prolongar hasta el último tramo del mismo. Desconocemos, con los datos actuales, el alcance que puede tener el lapso de algo más de una centuria que separa al grueso de las dataciones de Fuente Celada con la más moderna de todas ellas.

\section{Discusión y conclusiones}

Como se ha señalado anteriormente, tres son los aspectos fundamentales en los que se centra el trabajo. Por un lado, la atribución crono-cultural de Fuente Celada, la cual queda definida por los elementos ornamentales más significativos de las cerámicas recuperadas, pero sobre todo por el conjunto de dataciones absolutas obtenidas. Los datos revelan claramente dos fases diferenciadas: una neolítica, ceñida al norte de la intervención, y otra calcolítica, que se detecta por todo el área de intervención.

Todos estos indicios determinan un marco temporal amplio con un prolongado hiato de de dos milenios entre la ocupación neolítica y la calcolítica. La disociación temporal de ambas permite reconocer al menos dos fases distintas en el yacimiento. Los datos de ambas ocupaciones muestran 


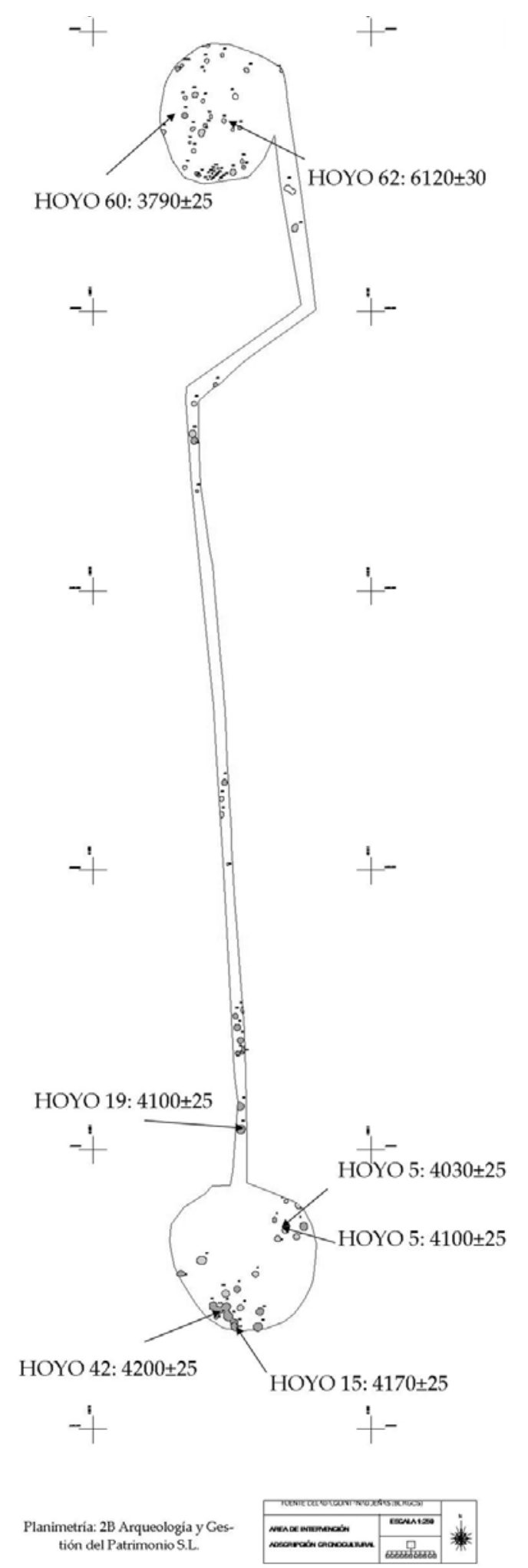

Figura 14.-Distribución en planta de las dataciones absolutas. diferencias, sobre todo por la menor capacidad y la práctica ausencia de fauna en los hoyos neolíticos. Precisamente, los hoyos calcolíticos, además de ser más grandes, contienen todos los residuos derivados de un espacio doméstico de producción, incluidos aquellos relacionados con el caserío. En este mismo espacio, indisociado del hábitat y el espacio doméstico, se reconocen dos episodios de amortización diferenciada, que podrían responder a los restos del algún tipo de consumo conspicuo. Las discrepancias entre unos hoyos y otros permiten suponer que, además de la diferencia cronológica, puede existir una orientación productiva distinta entre una ocupación y otra. No pretendemos extendernos en este argumento debido a lo reducido de la muestra neolítica (5 hoyos), así que centraremos la discusión en las particularidades del registro de época calcolítica.

Respecto al tipo de ocupación, no cabe ninguna duda sobre el uso del espacio como hábitat, a pesar de la aparente ausencia de unidades de habitación (cabañas), pues disponemos de indicios que contradicen esta falta: la presencia de fragmentos de manteado de barro utilizado en el revestimiento de cabañas y el registro de agujeros de poste. Además, la ausencia de evidencias directas de cabañas puede relacionarse con el proceso de formación-destrucción del yacimiento en el que las fases destructivas (limpiezas, reciclaje de elementos constructivos, erosión, labores agrícolas, etc.) han acabado con las evidencias acumuladas en los estratos superiores. En ese sentido, parece significativo el vacío reconocible entre los hoyos que incorporan manteado de barro entre sus rellenos. Una hipótesis plausible es la que considera que en este lugar se podían haber ubicado las unidades de hábitat. Esta consideración se ve reforzada por la distribución espacial de los elementos de molienda-trituración, que se ciñen a este mismo espacio. $\mathrm{Si}$ asumimos la hipótesis de que existe una tendencia a depositar los desechos domésticos en las proximidades de procesamiento de los productos, cabe asumir que la zona de transformación de los bienes subsistenciales se ubicaría en este espacio.

Junto a estas evidencias indirectas se reconocen otras propias de espacios domésticos. Los datos registrados corroboran la práctica de diferentes actividades económicas vinculadas a unidades de producción domésticas. Los hoyos aportan elementos arqueológicamente significativos, a tenor de las especies faunísticas presentes, sobre la acti- 
vidad ganadera y cinegética, en forma de productos consumidos y/o desechados. La agricultura se documenta de manera directa y testimonial, al menos de momento, a través de restos de cereal en el hoyo 35 , y de la presencia de elementos de molienda-trituración. En ese sentido, parece que los propios hoyos conforman espacios de almacenaje de productos vinculados a unidades de producción domésticas, con capacidad de almacenamiento de recursos en una escala reducida (menos de 700 litros) como norma.

La explotación de los recursos líticos del páramo está documentada en el yacimiento, aunque de manera marginal. Quizá esta actividad fuese realizada fuera del yacimiento, como atestiguan las numerosas estaciones de explotación de recursos líticos (31) que jalonan la parte alta del páramo según el Inventario Arqueológico de Castilla y León. No hay que desdeñar, no obstante, la actuación de procesos postdeposicionales que pudieron afectar particularmente a la distribución de la industria lítica (zonas de talla arrasadas por la erosión, arado, etc.).

Llama poderosamente la atención la elección del emplazamiento: en un alto, alejado de los espacios potencialmente más productivos situados en el fondo del valle. No obstante, salvo esta peculiaridad, no se detecta ningún tipo de diferencia significativa con los yacimientos calcolíticos de la Meseta Norte que ocupan normalmente espacios abiertos en las vegas de los valles (García Barrios 2007).

Más expresiva es la evidencia en cuanto a otra de las facetas destacadas del registro arqueológico recuperado en Fuente Celada: las inhumaciones en fosa. Es importante destacar que estas manifestaciones arqueológicas ponen de manifiesto maneras diversas de gestionar la muerte que se alejan de la aparente homogeneidad proporcionada por la vigencia del Megalitismo. En este sentido, el espacio inmediato al yacimiento se encuentra jalonado de megalitos. Llama la atención la convivencia de enterramientos segregados del poblado con otros integrados en el espacio de hábitat. Ambas expresiones parecen contradictorias si tenemos en cuenta que la monumentalidad de los megalitos permite dirigir el mensaje tanto dentro como fuera de los grupos locales. Por el contrario, las inhumaciones en fosa, en virtud de su menor visibilidad, aparentemente restringen su acción al ámbito intragrupal (Díaz del Río 2001). Es probable, a tenor de las dataciones, que los monumentos funerarios y los espacios de hábitat no fuesen estrictamente contemporáneos, sobre todo por el hiato de 2000 años que separan a la ocupación neolítica de la calcolítica. Sin embargo, lo esencial del argumento, más allá de las discrepancias formales o cronológicas, es que todas estas manifestaciones arqueológicas suponen prácticas funerarias sistematizadas. Esto es evidente en el caso del Megalitismo. Quizá lo sea algo menos en relación a las inhumaciones en fosa precampaniformes, aunque cada vez es mayor el número de estas manifestaciones arqueológicas dentro de los lugares de hábitat reproduciendo unos patrones semejantes (Delibes de Castro et al. 1988, Fabián García 1995, 2006, Blasco Bosqued et al. 2005, Liseau et al. 2008, Díaz del Río et al. 1997, García Barrios 2007, Esparza Arroyo et al. 2008).

Tal sistematización se puede relacionar con sociedades parentales de tipo genealógico (Vicent García 1990: 284-285). En otras palabras, son la expresión palpable de la configuración de grupos locales de filiación que reclaman su derecho de apropiación sobre los medios de producción (en particular, la tierra). En términos sociales este tipo de marco se traduce en la aparición de las sociedades de linajes cuyo fundamento es el parentesco genealógico (Meillassoux 1999). En este contexto, el grupo parental utiliza a los inhumados -ancestros- como justificación ideológica de dicha apropiación (Vicent García 1990), pero también como elemento sustancial para la reproducción social, tal y como manifiesta el consumo diferencial registrado en el hoyo 19. Los aspectos arqueológicos documentados informarían, entonces, del marco de relaciones sociales vigentes. Estas muestran la importancia de los medios de producción inmóviles para estas comunidades (Díaz del Río 1995: 107), constituidas ya como genuinas sociedades campesinas en las que el productor se encuentra directamente vinculado a la tierra (Vicent García 1990).

Además, tanto el yacimiento, a través de la construcción y amortización de los hoyos, como el entorno, donde se acumulan monumentos megalíticos y lugares de explotación y transformación de recursos líticos, demuestran una fuerte inversión en la transformación y adecuación del espacio para cumplir con los objetivos de producción y reproducción social del grupo. Esta inversión en "capital fijo" o "agrario" (Gilman y Thornes 1985: 188, 
Vicent García 1990, Díaz del Río et al. 1997: 108) no está en consonancia con la extrema movilidad propuesta para estas comunidades (Blasco et al. 1994, Bellido Blanco 1996: 87, Palomino Lázaro et al. 1997). La inversión de trabajo social en el medioambiente provoca su transformación en medio de producción, de tal modo que, desde ese momento, resulta más costoso su abandono y una nueva inversión en otro lugar que el mantenimiento de una productividad mínima (Díaz del Río 1995: 104).

Es por ello que consideramos que a finales del III milenio, el modo de vida campesino se encuen- tra consolidado en la Meseta Norte. Dentro de este marco, los distintos indicadores arqueológicos cobran sentido. El ejemplo de Fuente Celada ha proporcionado datos sobre la organización de la producción, así como de ciertos aspectos relacionados con la reproducción social. No obstante, quedan abiertas numerosas vías de investigación que han de ser integradas dentro de programas de investigación más amplios que se centren en la explicación de los procesos históricos que se encuentran detrás de la evidencia arqueológica de la que Fuente Celada no es más que una muestra.

\section{REFERENCIAS BIBLIOGRÁFICAS}

Álvarez Clavijo, P.; Ceniceros Herreros, J.; Ilarraza Tejada, J.A. (1996): Nuevos datos para la descripción del calcolítico en el Valle Alto-Medio del Ebro. II Congreso de Arqueología Peninsular (R. Balbín Berhmann, P. Bueno Ramírez, eds.), Fundación Rei Afonso Henriques, Zamora: 291-300

Apellaniz, J.M. (1974): El grupo de Los Husos durante la Prehistoria con cerámica en el País Vasco. Estudios de Arqueología Alavesa, tomo VII (monográfico).

Apellaniz, J.M.; Domingo Mena, D. (1987): Estudios sobre Atapuerca (Burgos): II. Los materiales de superficie del Santuario de la Galería del Sílex. Universidad de Deusto, Bilbao.

Arbizu Sagredo, M. (2001): Ficha del Inventario Arqueológico de Castilla y león. Fuente Celada (Alfoz de Quintanadueñas, Burgos). Servicio Territorial de Cultura de Burgos, Junta de Castilla y León, Burgos.

Arnaiz Alonso, M.A. (1989): Ficha del Inventario arqueológico de la provincia de Burgos. Servicio territorial de Cultura de Burgos. Junta de Castilla y León.

Arnaiz Alonso, M.A. (2005): Los testimonios neolíticos del Cerro de San Miguel (Burgos): Consideraciones sobre la ocupación de un espacio marginal. Estudios de Historia y Arte. Homenaje al Profesor D. Alberto C. Ibáñez Pérez, Universidad de Burgos, Burgos: 75-80.

Arnaiz Alonso, M.A.; EsparZa Arroyo, A. (1985): Un yacimiento al aire libre del Neolítico interior: el Altotero de Modúbar (Burgos). Boletín del Seminario de Estudios de Arte y Arqueología, LVI: 5-47.

ARnaiz Alonso, M.A.; PASCuAL, S.; RoJo, A. V. (1997): Los semejantes y los otros: la sepultura múltiple simultánea de Villayerno-Morquillas, Burgos. Nota preliminar. Boletín del Seminario de Estudios de Arte y Arqueología, LXIII: 49-69.

BARKER, P. (1977): Techniques of Archaeological Excavation. B.T. Batsford, Londres.

Bellido Blanco, A. (1996): Los campos de hoyos. Inicio de la economía agrícola en la Submeseta Norte. Studia Archaeologica, 85, Universidad de Valladolid, Valladolid.

Benet, N.; PÉrez, R.; SANTONJA, M. (1996): Evidencias campaniformes en el valle medio del Tormes. II Congreso de Arqueología Peninsular (R. Balbín Berhmann, P. Bueno Ramírez, eds.), Fundación Rei Afonso Henriques, Zamora: 449-470.

Blasco, C.; Baena, J.; Recuero, V. (1994): Los asentamientos. El Horizonte Campaniforme de la Región de Madrid en el centenario de Ciempozuelos (M.C. Blasco Bosqued, ed.), Universidad Autónoma de Madrid, Madrid: 47-73.

Blasco, M. C.; BAENA, J.; Ríos, P. (2007-2008): Materias primas de elementos de molienda como marcadores de la ampliación de las áreas de captación durante el Horizonte campaniforme. El ejemplo del Camino de las Yeseras. Veleia, 24-25, Tomo II: 755-769.

Blasco Bosqued, M.C.; Liesau Von Lettow-Vorbeck, C.; Delibes De Castro, G.; Baquedano Pérez, E.; Rodríguez Cifuentes, M. (2005): Enterramientos campaniformes en ambiente doméstico: el yacimiento del Camino de las Yeseras (San Fernando de Henares, Madrid). El Campaniforme en la Peninsula Ibérica y su contexto europeo (M.A. Rojo Guerra, R. Garrido Pena, I. García-Martínez de Lagrán, eds), Universidad de Valladolid, Valladolid: 457-473. 
BRonk RAMSEY, C. (2009): Bayesian analysis of radiocarbon dates. Radiocarbon, 51(1), 337-360.

BRonk Ramsey, C. (2010): Oxcal Program 4.1.5. [URL: https://c14.arch.ox.ac.uk/oxcal/OxCal.html]

CAMPILLO, D. (2001): Introducción a la paleopatología. Bellaterra, Barcelona.

CARAndini, A. (1997): Historias en la Tierra. Manual de excavación arqueológica, Crítica, Barcelona.

Carmona Ballestero, E. (2010): Prestigio y emulación en espacios marginales: la cerámica campaniforme de Paulejas (Quintanilla del Agua, Burgos). Universidad de Burgos, Burgos.

Castro, P.; Lull, V.; Micó, R. (1996): Cronología de la Prehistoria Reciente de la Península Ibérica y Baleares (c. 2800-900 cal ANE). BAR International Series, 652.

Delibes de CAstro, G. (1988): El enterramiento calcolítico en fosa de "El Ollar", Donhierro (Segovia). Espacio, Tiempo y Forma. Prehistoria, I: 227-238.

Delibes de Castro, G.; Benet Jordana, N.; Pérez Martín, R.; Zapatero Magdaleno, M. (1997): De la tumba dolménica como referente territorial, al poblado estable: notas sobre el hábitat y las formas de vida de las comunidades megalíticas de la Submeseta Norte. O Neolítico Atlántico e as orixes do megalitismo (A. Rodríguez Casal, ed.), Universidade de Santiago de Compostela: 779-808

Delibes de Castro, G.; Esparza Arroyo, A.; García Soto, E.; López Rodríguez, J. R.; Mariné Isidro, M. (1988): La colección arqueológica del padre Saturio González en Santo Domingo de Silos. Diputación de Burgos, Burgos.

Delibes de Castro, G.; FernÁndez Manzano, J. (2000): La trayectoria cultural de la Prehistoria Reciente (6400-2500 $\mathrm{BP})$ en la Submeseta Norte española: principales hitos de un proceso. Actas del III Congreso de Arqueología Peninsular. ADECAP, Porto: 95-122

Delibes de Castro, G.; Herrán Martínez, J.I. (2007): La Prehistoria. Diputación de Valladolid, Valladolid.

Delibes de Castro, G.; Herrán Martínez, J.I.; Santiago Pardo, J.; Val Recio, J. (1995): Evidence for Social Complexity in the Copper Age of the Northern Meseta. The Origins of Complex Societies in Late Prehistoric Iberia (K.T. Lillios, ed.), Ann Arbor, Michigan: 44-63.

Delibes de Castro, G.; Rodríguez Marcos, J.A. (2003): La "arqueología de Silos" punto de partida de las investigaciones sobre prehistoria reciente en la Meseta. Silos. Un milenio. Actas del Congreso Internacional sobre la Abadía de Santo Domingo de Silos (J.A. Fernández Flórez, ed.), Universidad de Burgos-Abadía de Silos, Santo Domingo de Silos.

DíAZ DEL Río, P. (1995): Campesinado y gestión pluriactiva del ecosistema: un marco teórico para el análisis del III y el II milenios a.C. en la Meseta peninsular. Trabajos de Prehistoria, 52 (2): 99-109.

DíAZ DEL Río, P. (2001): La formación del paisaje agrario: Madrid en el III y II milenios BC. Consejería de las Artes de la Comunidad de Madrid, Madrid.

Díaz del Río, P.; Consuegra, S.; Peña Chocarro, L.; Márquez, B.; Sampedro, C.; Moreno, R.; Albertini, D.; PINO, B. (1997): Paisajes agrarios prehistóricos en la meseta peninsular: el caso de "Las Matillas" (Alcalá de Henares, Madrid). Trabajos de Prehistoria, 54 (2): 93-111.

DíAz DEL Río, P.; Vicent, J.M. (2006): Movilidad, funcionalidad y usos del suelo en la Prehistoria Reciente. Arqueología Espacial, 26, pp. 21-36.

DietLer, M. (1995): Feast and commensal politics in the Political Economy: Food, Power, and Status in the Prehistoric Europe. Food and the status quest. An interdisciplinary perspective (P. Wiessner, W. Schiefenhövel, eds.), Berghanm Books, Providence, Oxford: 87-125

Domínguez Bolaños, A. (1991): Los Paradores de Castrogonzalo. Un yacimiento calcolítico y romano. Anuario del Instituto de Estudios Zamoranos Florián Ocampo, 8: 191-207.

Esparza Arroyo, A.; Delibes de Castro, G.; Velasco Vázquez, J.; Cruz Sánchez, P.J. (2008): Historia de un golpe en la cabeza: Sobre el enterramiento calcolítico del Hoyo 197 de "El Soto de Tovilla" (Tudela de Duero, Valladolid). Boletín del Seminario de Estudios de Arte y Arqueología, LXXIV: 9-48.

Estremera Portela, M.S. (2003): Primeros agricultores y ganaderos en la Meseta Norte: el Neolitico de la Cueva de La Vaquera (Torreiglesias, Segovia). Junta de Castilla y León, Zamora.

FABIÁN GARCíA, F.J. (1995): El aspecto funerario durante el Calcolítico y los inicios del a la Edad del Bronce en la Meseta Norte. Universidad de Salamanca, Salamanca.

FABIÁn GARCíA, F.J. (2006): El IV y III milenio a.C. en el Valle del Amblés (Ávila). Junta de Castilla y León, Valladolid.

García BArrios, A.S. (2004-2005): El espacio doméstico en la Prehistoria Reciente de la Meseta: el testimonio de las cabañas de la Edad del Cobre en el Valle Medio del Duero. Lancia, 6: 59-75.

GARCía BARrios, A.S. (2007): Los inicios de la Edad del Cobre en el Valle Medio del Duero: Una aproximación a los modos de vida en el centro de la Meseta en los albores de la metalurgia. Tesis Doctoral, Universidad de Valladolid, Valladolid.

Garrido Pena, R. (2000): El Campaniforme en la Meseta Central de la Península Ibérica (c. 2500-2000 a.C.). BAR International Series, 892, Oxford. 
Gilman, A.; Thornes, J.B. (1985): Land-use and Prehistory in South-East Spain. George Allen \& Unwin, Londres.

GutiérRez-Avellanosa de PABlo, A. (2008): Los restos óseos humanos recuperados en la excavación arqueológica del yacimiento de Fuente Celada. Anexo. Excavación Arqueológica. Yacimiento de Fuente Celada (Quintanadueñas). Obras de Ejecución del Parque Eólico de "El Páramo” (G. Martínez Díez, C. Diez Pastor, M.C. Alameda Cuenca-Romero, eds.), Informe técnico, Servicio Territorial de Cultura de Burgos, Junta de Castilla y León, Burgos.

Gutiérrez Palacios, A. (1962): El poblado eneolítico de La Peña del Bardal, Diego-Álvaro (Ávila). Campaña de 1958. Congreso Nacional de Arqueología (Barcelona 1960).

GutiÉrRez SÁEz, C. (1998): Aportaciones del estudio de la industria lítica a la comprensión del fenómeno calcolítico. Yacimiento de Llanete de los Moros (Montoro, Cordoba). Espacio, Tiempo y Forma. Prehistoria y Arqueología, 11: 191-210.

Harris, E.C. (1991): Principios de estratigrafia arqueológica, Crítica, Barcelona.

Hayden, B. (1995): Feasting in prehistoric and traditional societies. Food and the status quest. An interdisciplinary perspective (P. Wiessner, P, W. Schiefenhövel, eds.), Berghman Books, Providence, Oxford: 127-147.

Herrán Martínez, J.I. (1986): El yacimiento calcolítico de Los Cercados en Mucientes. Sobre los comienzos de la metalurgia en el Valle Medio del Duero. Memoria de Licenciatura, Universidad de Valladolid, Valladolid.

Herrán Martínez, J.I.; Fernández JimÉnez, J.M.; PÉrez Rodríguez, F.J. (1995): Los comienzos de la metalurgia en el bajo Pisuerga palentino. Actas del III Congreso de Historia de Palencia (M.V. Calleja González, ed.), Diputación Provincial de Palencia, Palencia: 67-91

Herrán Martínez, J.I.; Santiago Pardo, J. (1989): Un puñal de cobre precampaniforme de Muriel de Zapardiel (Valladolid). Boletín del Seminario de Estudios de Arte y Arqueología, LV: 199-206.

Hurtado PÉRez, V. (1982): Relaciones culturales entre el sudeste francés y La Pijotilla (Badajoz) en el Calcolítico: Las pastillas repujadas y el campaniforme cordado. Habis, 13: 189-209.

Liesau, C.; Blasco, C.; Ríos, P.; Vega, J.; Menduiña, R.; Blanco, J. F.; Baena, J.; Herrera, T.; Petri, A.; Gómez, J.L. (2008): Un espacio compartido por vivos y muertos: El poblado calcolítico de fosos de Camino de las Yeseras (San Fernando de Henares, Madrid). Complutum, 19 (1): 97-120.

Lizcano Prestel, R.; CÁmara Serrano, J.A. (2004): Producción económica y sedentarización. El registro arqueológico del Polideportivo de Martos (Jaén). Sociedades Recolectoras y Primeros productores. Actas de las Jornadas temáticas andaluzas de Arqueología, Junta de Andalucía.

LóPEz LóPEZ, G. (2005): Cadenas operativas líticas y cambio tecnológico en la Prehistoria Reciente: el yacimiento de Barranco del Herrero (San Martín de la Vega, Madrid). Actas do IV congresso do Arqueologia Peninsular. Do Epipaleolítico no Calcolítico na Peinsula Iberica, Universidade do Algarve, Faro: 307-319

LÓPEZ PlaZA, S.; PIÑEl, C. (1978): El poblado eneolítico de Fontanillas de Castro (Zamora): primera aportación a su estudio. Zephyrus, XXLVIII-XXIX: 191-205.

Martínez Díez, G.; Diez Pastor, C.; Alameda Cuenca-Romero, M.C. (2008): Excavación Arqueológica. Yacimiento de Fuente Celada (Quintanadueñas). Obras de Ejecución del Parque Eólico de "El Páramo". Informe técnico, Servicio Territorial de Cultura de Burgos. Junta de Castilla y León, Burgos.

MeILlassouX, C. (1999): Mujeres, graneros y capitales. Economía doméstica y capitalismo. Siglo XXI, Madrid.

Morales MuÑIz, A. (1992): Estudio de la fauna del yacimiento calcolítico de "Las Pozas" (Casaseca de las Chanas, Zamora). Boletín del Seminario de Estudios de Arte y Arqueología, LVIII: 65-96.

Morales Muñz, A.; Liesau Von Lettow-Vorbeck, C. (1994): Arqueozoología del Calcolítico en Madrid: ensayo crítico de síntesis. El Horizonte Campaniforme de la Región de Madrid en el centenario de Ciempozuelos (M.C. Blasco Bosqued, ed.), Universidad Autónoma de Madrid, Madrid: 227-247.

Municio GonzÁlez, L. (1988): El Neolítico en la Meseta Central española. El Neolítico en España (P. López, ed.), Cátedra, Madrid: 299-328.

Ortega, A. I.; Juez, L.; Carretero, J. M.; Ortega, M. C.; Arsuaga, J.L.; Pérez GonzÁlez, A. (2008): El Neolítico en la nueva secuencia estratigráfica del yacimiento del Portalón de Cueva Mayor (Sierra de Atapuerca, Burgos). $I V$ Congreso del Neolítico Peninsular (M.S. Hernández Pérez, J.A. Soler Díaz, J.A. López Padilla, eds.), Museo Arqueológico de Alicante, Alicante: 221-229

Palomino LÁzaro, A. (2001): Informe de la Prospección arqueológica del Parque Eólico “El Páramo”, en el Alfoz de Quintanadueñas. Informe técnico, Servicio Territorial de Cultura de Burgos. Junta de Castilla y León, Burgos.

Palomino lázaro, A.; Abarquero Moras, J.; Negredo García, M.J. (1997): La primera colonización estable de las tierras ribereñas del Duero en el sudeste de la provincia de Burgos: el poblamiento calcolítico. Numantia, 8: 63-84.

Palomino LÁzaro, A.; Martínez GonzÁlez, M.G. (2008): Excavación de sondeos arqueológicos en el yacimiento "Molino de Arriba", con motivo de la modificación puntual del Sector 2 II Fase, en Buniel (Burgos). Informe técnico, Servicio Territorial de Cultura de Burgos, Junta de Castilla y León, Burgos. 
Pascual Blanco, S.; Martínez Díez, G. (2008): Sondeos arqueológicos en el yacimiento de Fuente Celada (Alfoz de Quintanadueñas). Informe técnico, Servicio Territorial de Cultura de Burgos, Junta de Castilla y León, Burgos.

Pérez Rodríguez, F.J.; Fernández Gutiérrez, J.M.; Puertas Gutiérrez, F. (1990): Los Doce Cantos (Herrera de Pisuerga). Un yacimiento calcolítico precampaniforme en el Norte de la provincia de Palencia. II Congreso de Historia de Palencia (M.V. Calleja González, ed.), Diputación de Palencia, Palencia: 95-110

Pérez Rodríguez, F.J.; Sanz García, F.J.; Marcos Contreras, G.; Martín Carbajo, M.A.; Misiego Tejada, J.C. (1991): Intervención arqueológica en el yacimiento de "Los Bajos" (Vecilla de Trasmonte, Zamora). Anuario del Instituto de Estudios Zamoranos Florián Ocampo, 8: 149-173.

Priego, C.; Quero, S. (1992): El Ventorro, un poblado prehistórico en los albores de la metalurgia. Estudios de Prehistoria y Arqueología Madrileñas, 8 (monográfico).

Reimer, P.J.; Baillie, M. G.L.; Bard, E.; Bayliss, A.; Beck, J.W.; Blackwell, P.G.; Bronk Ramsey, C.; Buck, C. E.; Burr, G.S.; Edwards, R.L.; Friedrich, M.; Grootes, P. M.; Guilderson, T.P.; Hajdas, I.; Heaton, T.J.; HoGG, A.G.; Hughen, K.A.; Kaiser, K.F.; Kromer, B.; McCormac, F. G.; Manning, S. W.; Reimer, R. W.; Richards, D. A.; Southon, J. R.; Talamo, S.; Turney, C. S. M.; van der Plicht, J.; Weyhenmeyer, C.E. (2009): IntCal09 and Marine09 radiocarbon age calibration curves, 0-50,000 years cal BP. Radiocarbon, 51(4), 1111-1150.

Rodanés Vicente, J.M. (1999): Las Cuevas de Tragaluz y san Bartolomé (Sierra de Cameros, La Rioja). Los enterramientos en cueva en el Valle Medio del Ebro. Instituto de Estudios Riojanos, Gobierno de la Rioja, Logroño.

Rojo Guerra, M.A.; Garrido Pena, R.; García-Martínez de Lagrán, I.; Kunst, M. (2008a): Los recintos del poblado del Neolítico Antiguo de la Revilla del Campo (Ambrona, Soria). IV Congreso del Neolítico Peninsular (M.S. Hernández Pérez, J.A. Soler Díaz, J.A. López Padilla, eds.), Museo Arqueológico de Alicante, Alicante: 252258

Rojo Guerra, M.A.; Garrido Pena, R.; García Martínez de Lagrán, I.; Tejedor Rodríguez, C. (2008b): Los primeros agricultores y ganaderos del interior peninsular. Diez años de investigaciones en el valle de Ambrona (Soria). Ayto. de Miño de Medinaceli, Junta de Castilla y León, Caja Duero y Adema, Soria.

Rojo Guerra, M.A.; Garrido Pena, R.; Morán Dauchez, G.; Kunst, M. (2004): El Campaniforme en el valle de Ambrona (Soria, España). Dinámica del poblamiento y aproximación a su contexto social. Graves and funerary rituals during the Late Neolithic and Early Bronze Age in Europe (2700-200 a.C.). Proceedings of the international Conference held at the Cantonal Archeological Museum, Sion (Switzerland), BAR International Series, Oxford

Rojo Guerra, M.A.; Kunst, M.; Garrido Pena, R.; García-Martínez de Lagrán, I.; Morán Dauchez, G. (2005): Un desafio a la eternidad: tumbas monumentales en el valle de Ambrona. Junta de Castilla y León, Valladolid.

VAL ReCiO, J.D. (1992): El yacimiento calcolítico precampaniforme de Las Pozas en Casaseca de las Chanas (Zamora). Boletín del Seminario de Estudios de Arte y Arqueología, LVIII: 47-62.

VAl Recio, J.; Herrán Martínez, J.I. (1994): El Calcolítico precampaniforme en el Duero Medio. Origens, estruturas e relaçoes das Culturas Calcolíticas da Peninsula Iberica. Actas das Culturas Calcolíticas da Peninsula Ibérica. Actas das I Jornadas Arqueologicas de Torres Vedras (M. Kunst, ed.), Trabahlos de Arqueología: 293-304

Valiente Malla, J. (1996): Una cabaña doble del calcolítico en la Loma del Lomo (Cogolludo, Guadalajara). II Congreso de Arqueología Peninsular (R. Balbín Berhmann, R, P. Bueno Ramírez, eds.), Fundación Rei Afonso Henriques, Zamora: 495-507

Verges, J. M.; Allué, E.; Angelucci, D. E.; Burjachs, F.; Carrancho, A.; Cebria, A.; Expósito, I.; Fontanals, M.; Moral, S.; Rodríguez, A.; Vaquero, M. (2008): Los niveles neolíticos de la cueva de El Mirador (Sierra de Atapuerca, Burgos): nuevos datos sobre la implantación y el desarrollo de la economía agropecuaria en la Submeseta norte. IV Congreso del Neolítico Peninsular (M.S. Hernández Pérez, J.A. Soler Díaz, J.A. López Padilla, eds.), Museo Arqueológico de Alicante, Alicante: 418-427.

ViCENT GARCíA, J.M. (1990): El Neolitic: tranformacions socials i economiques. El canvi cultural a la Prehistòria (J. Anfruns, E. Llobet, eds.), Columna, Barcelona: 241-293.

ViCENT GARCÍA, J.M. (1995): Early social complexity in Iberia: some theoretical remarks. The origins of Complex Societies in Late Prehistoric Iberia (K.T. Lillios, ed.), Ann Arbor, Michigan: 177-183.

ViCENT GARCíA, J.M. (1998): La prehistoria del modo tributario de producción. Hispania, LVIII/3: 823-839.

Yravedra Sainz de los Terreros, J.; Macías Ramos, R.; Consuegra Rodríguez, S.; Díaz del Río, P. (2008): Anillos para una mina. Industria ósea y fauna de la Mina de Sílex neolítica de Casa Montero (Madrid). IV Congreso del Neolítico Peninsular (M.S. Hernández Pérez, J.A. Soler Díaz, J.A. López Padilla, eds.), Museo Arqueológico de Alicante, Alicante: $240-247$ 